\title{
Final Report: \\ DoE SBIR Phase 2 Low-Cost Small Diameter NMR \\ Technologies for In-Situ Subsurface Characterization and Monitoring
}

Project Funded by: DOE Grant DE-FG02-07ER84931

\author{
Prepared by: \\ Vista Clara Inc. \\ 12201 Cyrus Way, Suite 104 \\ Mukilteo, WA 98275 \\ Phone: 425-493-8122 \\ Fax: 425-493-8123 \\ David O. Walsh, Ph.D. \\ davewalsh@vista-clara.com
}

September 3, 2010 


\section{Executive Summary}

In this Phase 2 SBIR program, Vista Clara successfully developed and field-tested small diameter NNR logging tools for subsurface characterization and monitoring. This effort involved the design and development surface electronics, a winch with $470 \mathrm{ft}$ cable, and three interchangeable downhole probes: a 3.5" diameter borehole NMR probe, a 1.67" diameter borehole NMR probe, and a 2.5" diameter NMR probe that can be deployed using a Geoprobe direct push machine. The 3.5" probe was tested extensively over a 6 week period including 4" to 8" boreholes in Washington, Idaho, Nebraska, Colorado, Kansas, Connecticut and Massachusetts. The field test campaign was highly successful. The 1.67" probe was assembled, tested and calibrated in the laboratory. The 2.5" Geoprobe probe is in final assembly and testing at the time of this report.

The completed Phase 2 R\&D program has resulted in the first NMR logging tool that can be deployed in boreholes of 4" diameter, the first NMR logging tool that can be deployed in boreholes on 2" diameter, and the first NMR logging tool that can be deployed by a direct push machine. These small diameter tools make NMR logging technically and economically feasible, for the first time. Previously available NMR logging tools were developed for oilfield applications and are prohibitively large and expensive for the majority of near surface groundwater characterization problems.

\section{Summary of Phase 2 Technical Objectives and Results}

\subsection{Phase II Technical Objectives (copied verbatim from the Phase 2 proposal):}

The goal of the Phase II R\&D effort is to develop and demonstrate small diameter, lowcost borehole and cone penetrometer NMR instrumentation for subsurface characterization and monitoring. The Phase II Technical Objectives are organized to address specific milestones in the research and development process:

\section{1) Design, assemble, integrate and test a borehole NMR instrument with 2.5" diameter NUMAR magnet/coil sensor. (Year 1)}

$>$ Assemble and program a PXI-based NMR spectrometer for acquiring downhole NMR data.

$>$ Assemble and integrate a $5 \mathrm{~kW}$ class-D RF power amplifier with 50-ohm impedance matching output.

$>$ Design, assemble and integrate a 2.5" diameter x 4' long NUMAR magnet/coil assembly with matching, isolation, tuning, switching, pre-amp, and de-Qing circuitry. 
$>$ Design and assemble a prototype borehole cabling and transmission system including digitally-controlled winch, 150m custom multi-conductor cable, and waterproof high-voltage connectors.

Design and assemble a 3.25" diameter x 6' long borehole canister with waterproof cable connectors.

$>$ Integrate and test all components in the laboratory.

2) Design, assemble, and test a 1.75" diameter cone penetrometer NMR sonde. (Year 1)

$>$ Design and assemble an NMR cone-penetrometer sonde with a dummy 1.25 " diameter x 4' long NUMAR sensor package.

$>$ Design and integrate internal electrical cabling and connector system, to interface with Vista Clara's surface-based NMR spectrometer.

3) Test the prototype borehole and cone penetrometer NMR sensors at the Hanford Site. (Year 1)

$>$ Test the 2.5 " diameter borehole NMR sensor in a 4" monitoring well at the Hanford Site in Washington.

$>$ Test the cone penetrometer NMR sonde at the Hanford site.

4) Develop a suite of post-processing software for NMR signal processing and hydrological analysis of downhole NMR data. (Year 2)

5) Complete the engineering and assembly of the borehole and cone penetrometer NMR instrumentation (Year 2)

$>$ Design and manufacture a rugged, commercial-ready custom armored transmission cable, with completely through-winch signal routing, and custom winch contactors if required.

$>$ Complete the manufacture of 1.25" diameter, 2.5" diameter and 5.0" diameter borehole sensors and the cone pentrometer sonde.

6) Demonstrate the borehole and cone-penetrometer NMR instruments though a campaign of field-tests at DoE facilities and other sites to be selected by the US Geological Survey and our existing surface NMR customers in government and the private sector. (Year 2) 


\subsection{Summary of Phase II Results:}

The Phase 2 program objectives have been largely met. We developed the core NMR instrumentation, and extensively field-tested the instrumentation with a 3.5" diameter NMR probe to depths up to $130 \mathrm{~m}$. The field test campaign included boreholes in Washington, Idaho, Kansas, Nebraska, Colorado, Connecticut and Massachusetts. Detailed field test results are described in Section 4 of this report.

Additionally we assembled and tested a 1.7" diameter borehole NMR probe in the laboratory. This probe is now calibrated and ready for research and commercial operations. We plan to log 2" PVC boreholes in Washington State and Kansas in September and October 2010.

We have also had 2.5" diameter packaging designed and manufactured by Geoprobe Inc., for direct push NMR measurements using Geoprobe machines. This design is much simpler and less expensive than the original cone penetrometer design developed by Battelle. Most notable is the operation, which uses the Geoprobe machine to create the borehole. The probe is then lowered to the bottom of the borehole, exposed to the formation, and NMR logging is performed on the way up, as the Geoprobe drill rods are withdrawn from the ground. The Geoprobe packaging was pressure tested on a lab bench to 60PSI (approximately 33m depth rating), and also tested with a Geoprobe machine in Salina KS to ensure operability. As of mid-August 2010, Vista Clara have assembled the downhole electronics and anticipate that the Geoprobe NMR probe will be assembled and tested by the $2^{\text {nd }}$ week of September 2010 .

(All work performed after August 13, 2010 has been funded by Vista Clara using a portion of our reserved fee for this project.)

Two specific objectives that have not been met are testing of the 1.7" probe and the 2.5" Geoprobe sensor in actual boreholes. Laboratory testing of the 1.7" probe in a half-filled water barrel have been performed and are sufficient to characterize the performance and operability of the sensor. The 1.7" probe will be tested for the first time in a 2" borehole in Burlington WA, in September 2010. The Geoprobe NMR sensor will be first used in Lawrence KS in October 2010 as part of a new Phase 1 STTR project involving Stanford University and the Kansas Geological Survey. Also, we did not have time to construct the largest (5") diameter NMR probe, but the smaller probes presented a much larger challenge in terms of sensitivity and engineering. We have a design for a 4.5 " probe and can manufacture it whenever a customer has a need for it.

We also made some achievements that went beyond our Phase 2 proposal. These include:

- Implementation of multi-channel acquisition and processing for adaptive cancellation of radiofrequency interference (Patent Pending).

- Implementation of remotely switched tuning to enable acquisition in two cylindrical shells at two frequencies.

- A minimum echo spacing of $1.25 \mathrm{~ms}$, which is competitive with the Schlumberger MRX NMR logging tool. 
- Fully connectorized cables and probes, to enable quick and easy change of probes.

\section{Vista Clara Small Diameter Downhole NMR Instrumentation}

The Phase 2 R\&D Program resulted in a field-worthy prototype downhole NMR instrument, that is nearly at the level of a commercial geophysical instrument. The main components of the instrumentation are shown in Figure 1. The system consists of a shock-mounted rack electronics system, which includes the data acquisition system and RF power amplifier, a custom multi-core cable and cable winch, and various interchangeable probes for use in boreholes (2" ID to 8" ID) and/or with a Geoprobe cone penetrometer system. Other parts of the system not shown in Figure 1 include the 1.7" diameter borehole NMR probe, a laptop computer for control of data acquisition, and a portable generator which is normally used to power the system. The system can also run on $120 \mathrm{~V} 60 \mathrm{~Hz}$ AC power if it is available.

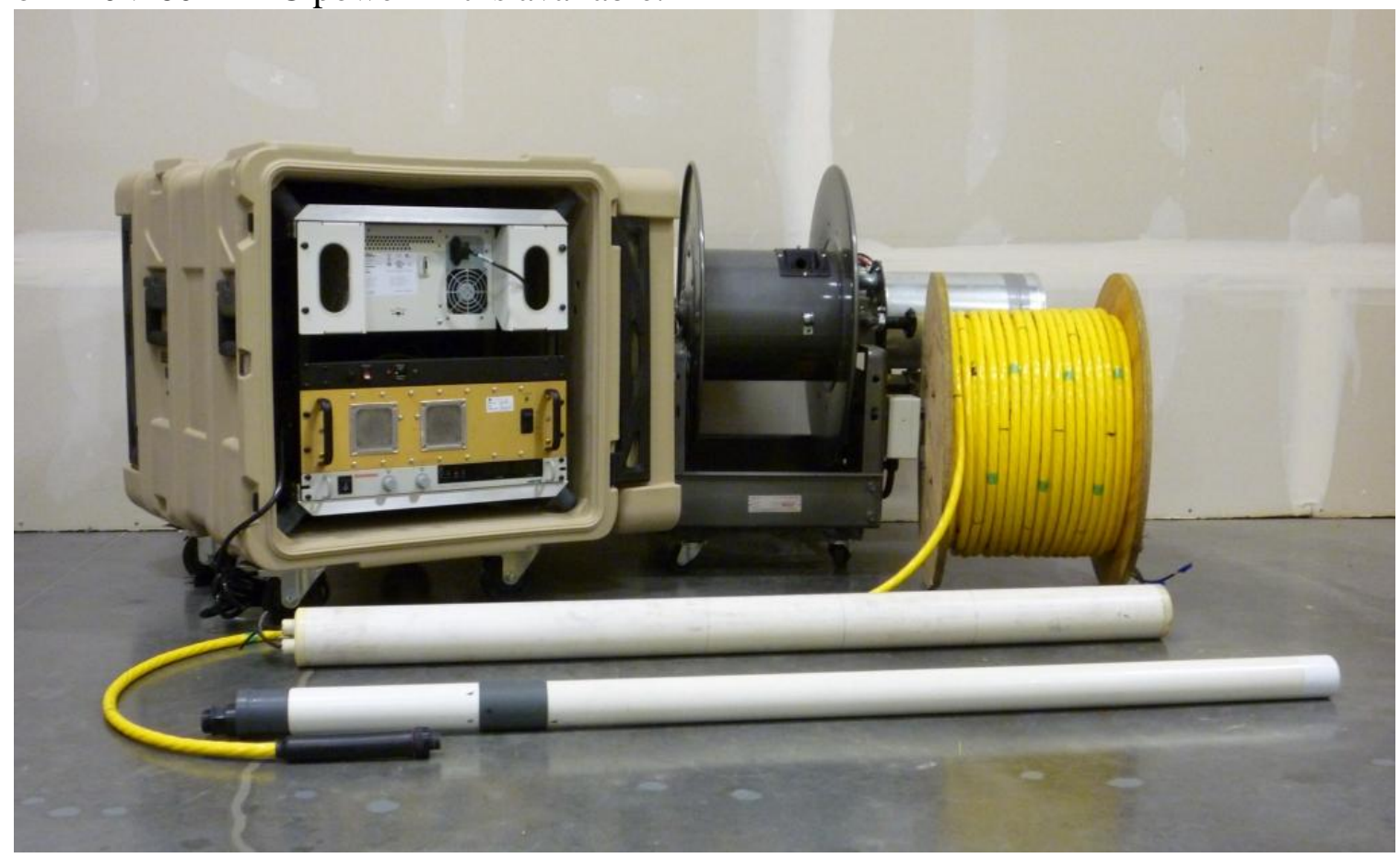

Figure 1: Components of Phase 2 downhole NMR instrument. Left: Shock mounted rack electronics including data acquisition system and RF power amplifier. Center: Motorized cable winch. Right: 470' custom multi-core cable with waterproof connector. Foreground: 2.5" Geoprobe NMR probe and 3.5" borehole NMR probe.

\section{Field Test Results}

This section provides a summary of the results of the principal field-testing of our 3.5" diameter borehole NMR tool, in April and May 2010. We wish to thank the following 
persons and organizations who facilitated these field tests, and who in many cases also assisted with data collection and interpretation:

Boise State University (Warren Barrash)

$>$ Central Platte Natural Resources District of Nebraska (Duane Woodward)

$>$ CSIRO (Andrew Fitzpatrick)

$>$ Kansas Geological Survey (Jim Butler)

$>$ Lawrence Berkeley National Laboratory (Kenneth Williams)

$>$ US Geological Survey Nebraska (Jim Cannia)

$>$ US Geological Survey Water Resources Division, Branch of Geophysics (John Lane, Carole Johnson)

We performed the principle field trials for our borehole NMR instrumentation April and May of 2010. These field tests utilized our 3.5" diameter borehole sensor, in PVC cased and uncased hard rock boreholes ranging from 4" to 8" diameters.

Of particular interest, we were able to log a 128m deep borehole in Nebraska that had been logged earlier this year by Schlumberger using their CMR tool, enabling a direct comparison between our tool and the much more expensive Schlumberger NMR tool.

The borehole NMR instrumentation proved itself to be robust throughout the field test campaign. We suffered a single hardware failure in approximately 6 weeks of testing, and that one failure was repaired on site in less than 2 hours.

The results from each of the field tests are summarized below.

\section{Lexington Nebraska: April 8 and April 24- 25, 2010.}

Our cooperators were the USGS and the Central Platte Natural Resources District. Many thanks to Jim Cannia of the USGS and Duane Woodward of the CPNRD for facilitating these field tests.

A $128 \mathrm{~m}$ deep PVC-cased borehole was installed at the site in early 2010. The

Schlumberger borehole NMR tool (CMR) was used to log this borehole while it was open and filled with drilling mud, and immediately prior to the installation of PVC casing. (The Schlumberger logging was done under a NSF-sponsored R\&D grant to Stanford University, with Rosemary Knight as the PI). Vista Clara has also previously performed extensive surface NMR surveys at this site, and other surface and borehole geophysical tools have been used to characterize this site. So this particular borehole provided an exceptional opportunity to compare the Vista Clara slimhole NMR instrument to the much larger and more expensive Schlumberger borehole NMR tool at a wellcharacterized site.

The borehole itself was PVC cased to a depth of 130m, with 6" diameter PVC in the top $30 \mathrm{~m}$ and 4" diameter PVC below 30m. The well was screened the entire length below $10 \mathrm{~m}$. 
We performed a preliminary NMR $\log$ of the top 25m of the well on April 8, 2010. We returned to this site on April 24 after completing other borehole NMR tests in Kansas and Colorado, to log the entire $128 \mathrm{~m}$. Photos of the borehole NMR instrumentation at the Lexington NE site on April 8 are shown in Figures $2-4$.

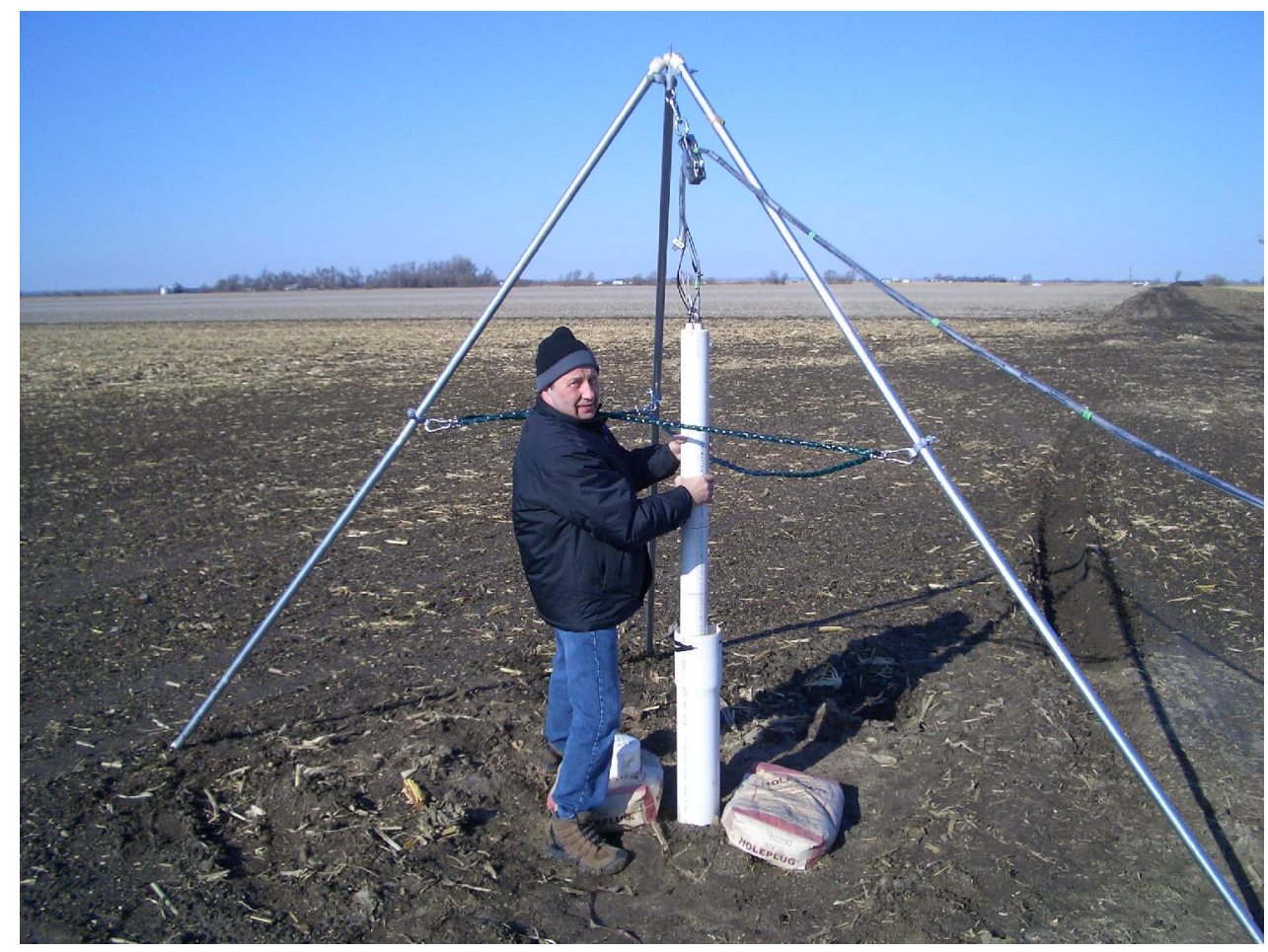

Figure 2: Vista Clara employee Igor Frid holding the 3.5" diameter borehole NMR probe at the top of the casing, April 8, 2010. 


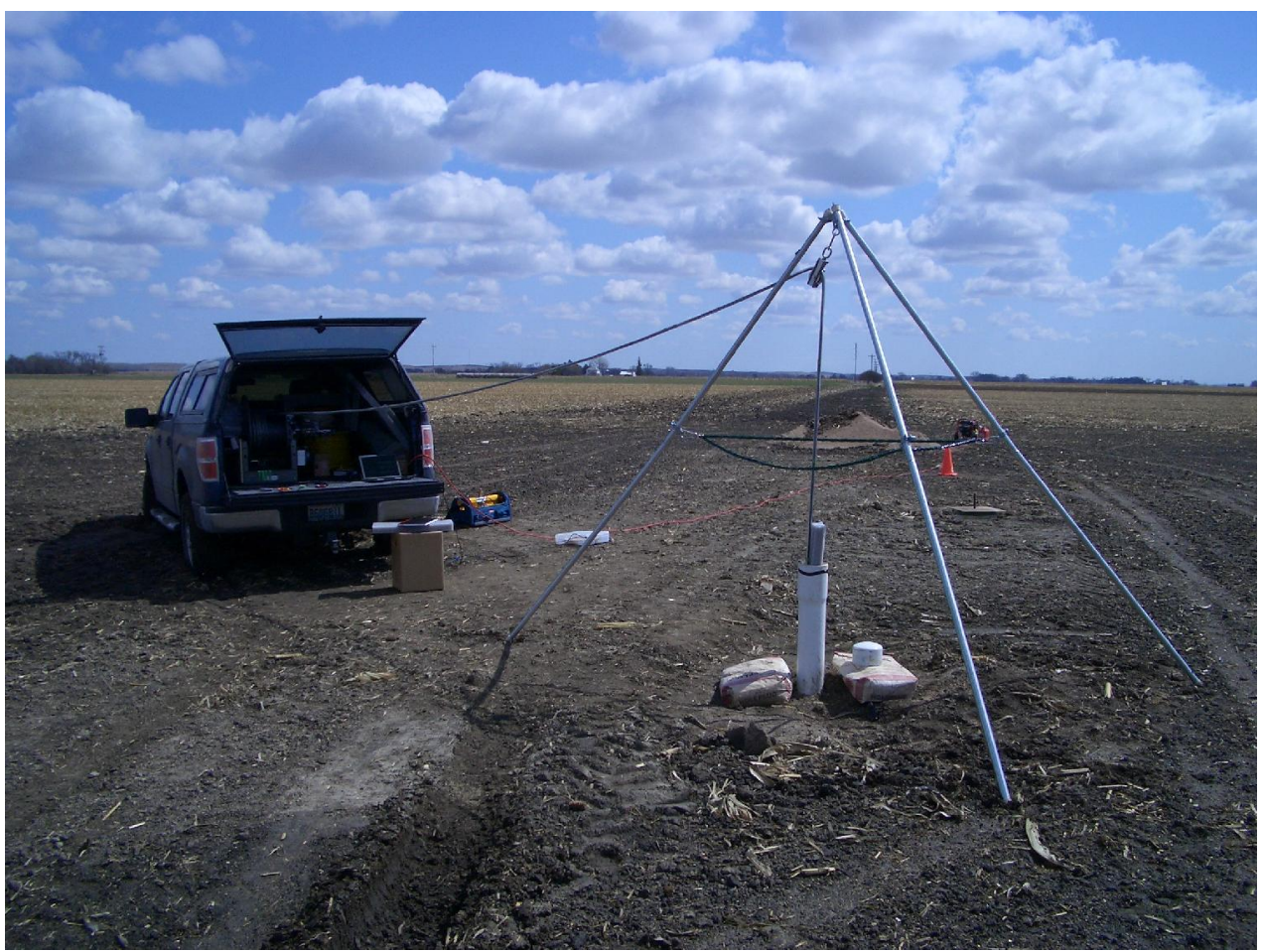

Figure 3: Overview of the instrumentation with the probe below ground level.

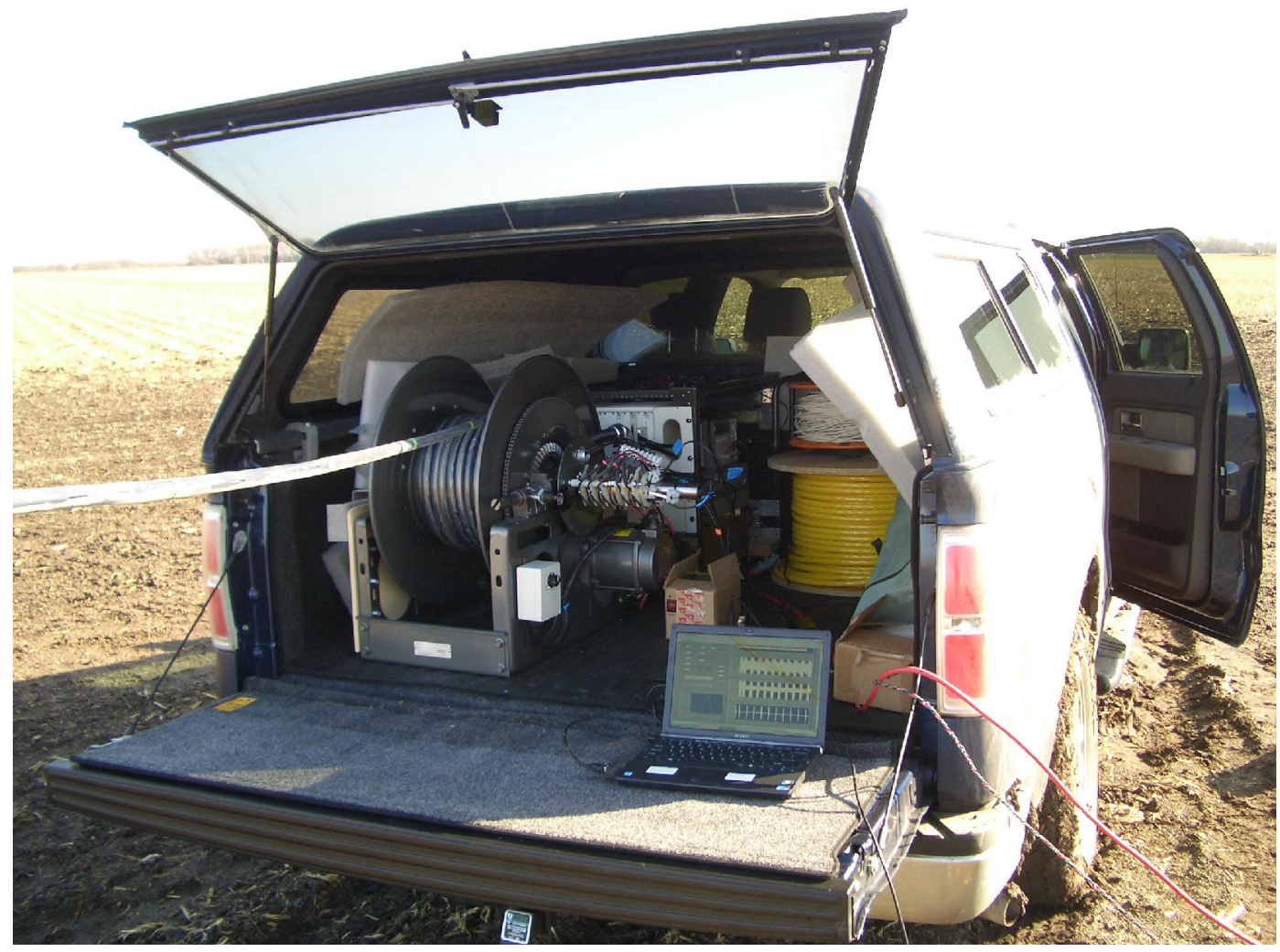

Figure 4: Close up view of surface electronics.

The data on April 8 were acquired using the following sequence parameters: 
Cable length $=100$ feet

Echo spacing $=2.5 \mathrm{~ms}$

N_stack $=75$ per depth interval

20 minutes per depth interval

$1 \mathrm{~m}$ intervals

logging rate $=3 \mathrm{~m} /$ hour

We also performed several measurements of background noise, and measurements in the saturated gravel with different $\operatorname{Tr}$ values. From these we determined that a $\operatorname{Tr}$ of $6 \mathrm{~s}$ was sufficient to obtain full T1 relaxation.

The borehole log of the top 26m on April 8 is shown in Figure 5. This result is consistent with the driller's description of lithilogy (silt and clay in the top $10 \mathrm{~m}$, gravel and sand from $10 \mathrm{~m}-24 \mathrm{~m}$, with clay at $21-22 \mathrm{~m}$ ). The standing water level in the well was at $5 \mathrm{~m}$. The borehole NMR log provides surprising detail on water content in the vadose zone (above 5m).
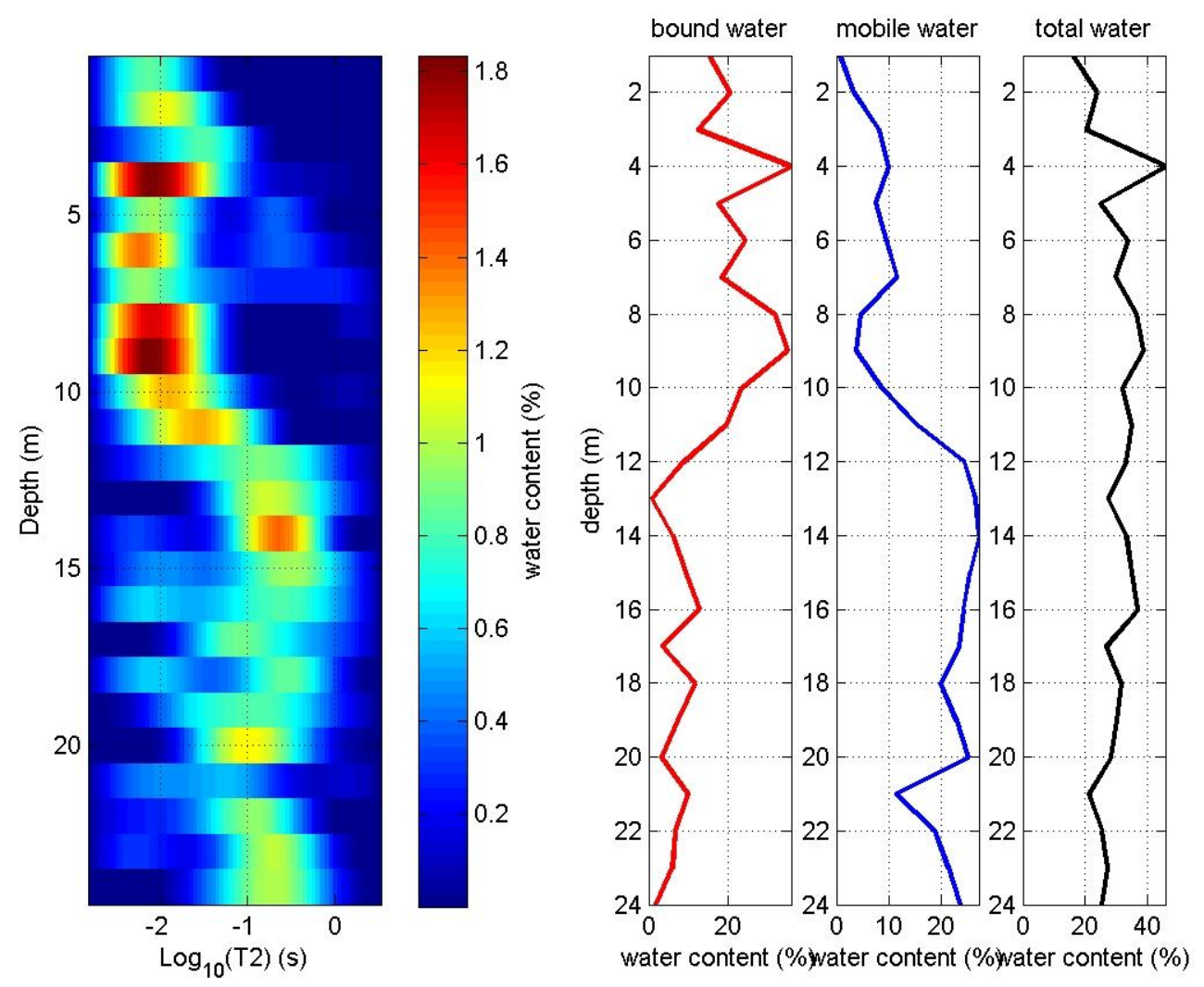

Figure 5: Borehole NMR log of site 58b, Lexington NE, April 8, 2010.

The spin echo data train from a "silty clay" layer at $8 \mathrm{~m}$ and its multi-exponential water content fit are shown in Figure 6, and spin echo data and multi-exponential fit for a gravel layer at $15 \mathrm{~m}$ are shown in Figure 7. 

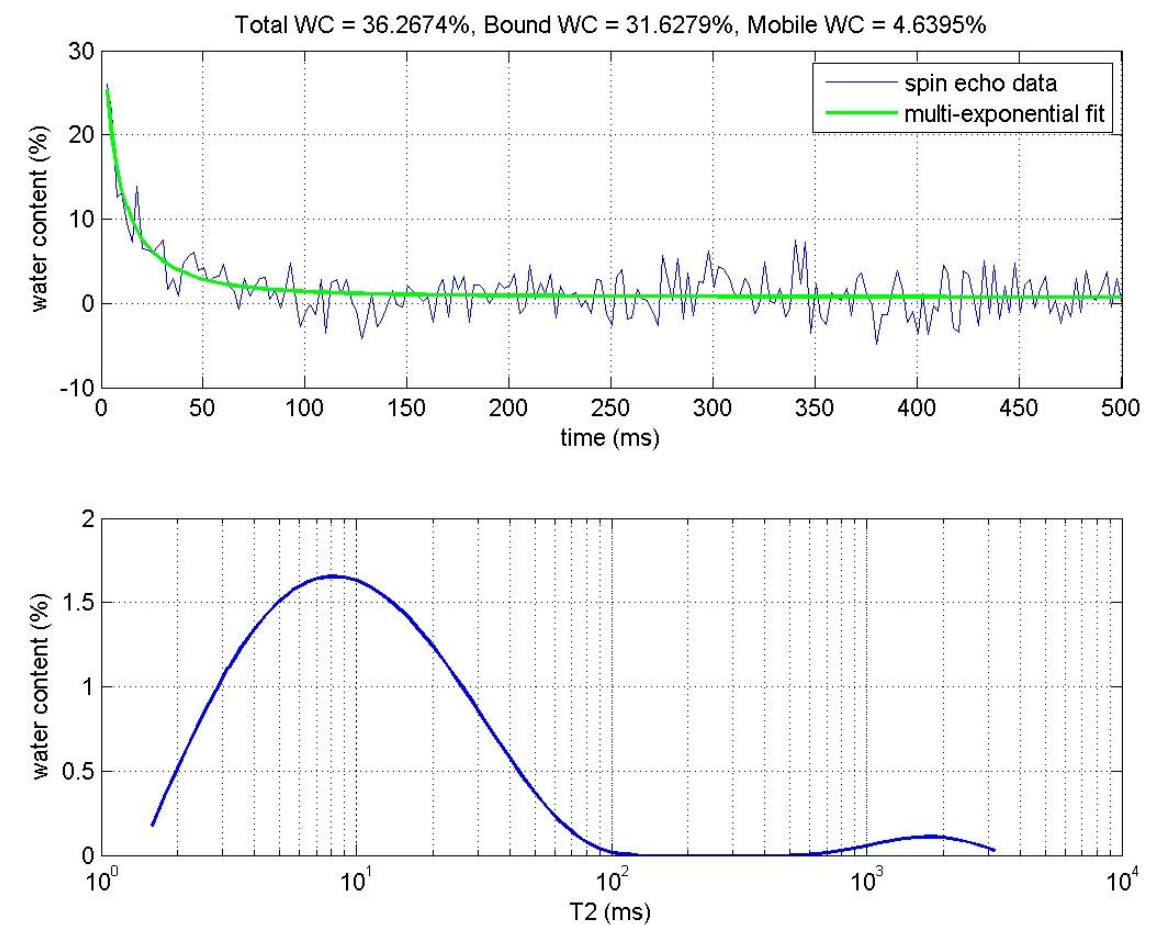

Figure 6: Spin echo data and multi-exponential fit for "silty clay" at 8m.
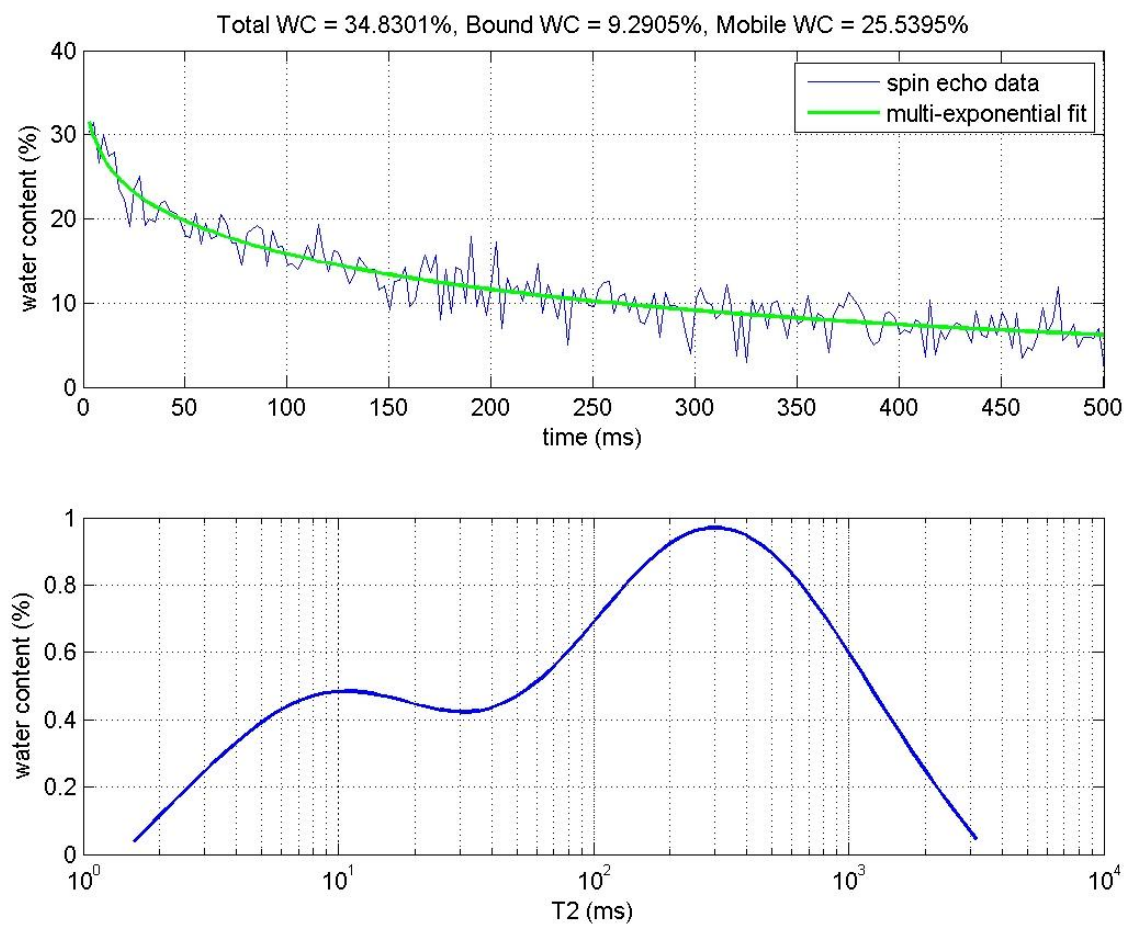

Figure 7: Spin echo data and multi-exponential fit for "gravel" at $15 \mathrm{~m}$. 
We returned to Lexington NE on April 24 to log the entire borehole. We switched from the 100' long cable that we had used on April 8 to a 470' cable. A photo of the instrumentation at the site on April 24 is shown in Figure 8.

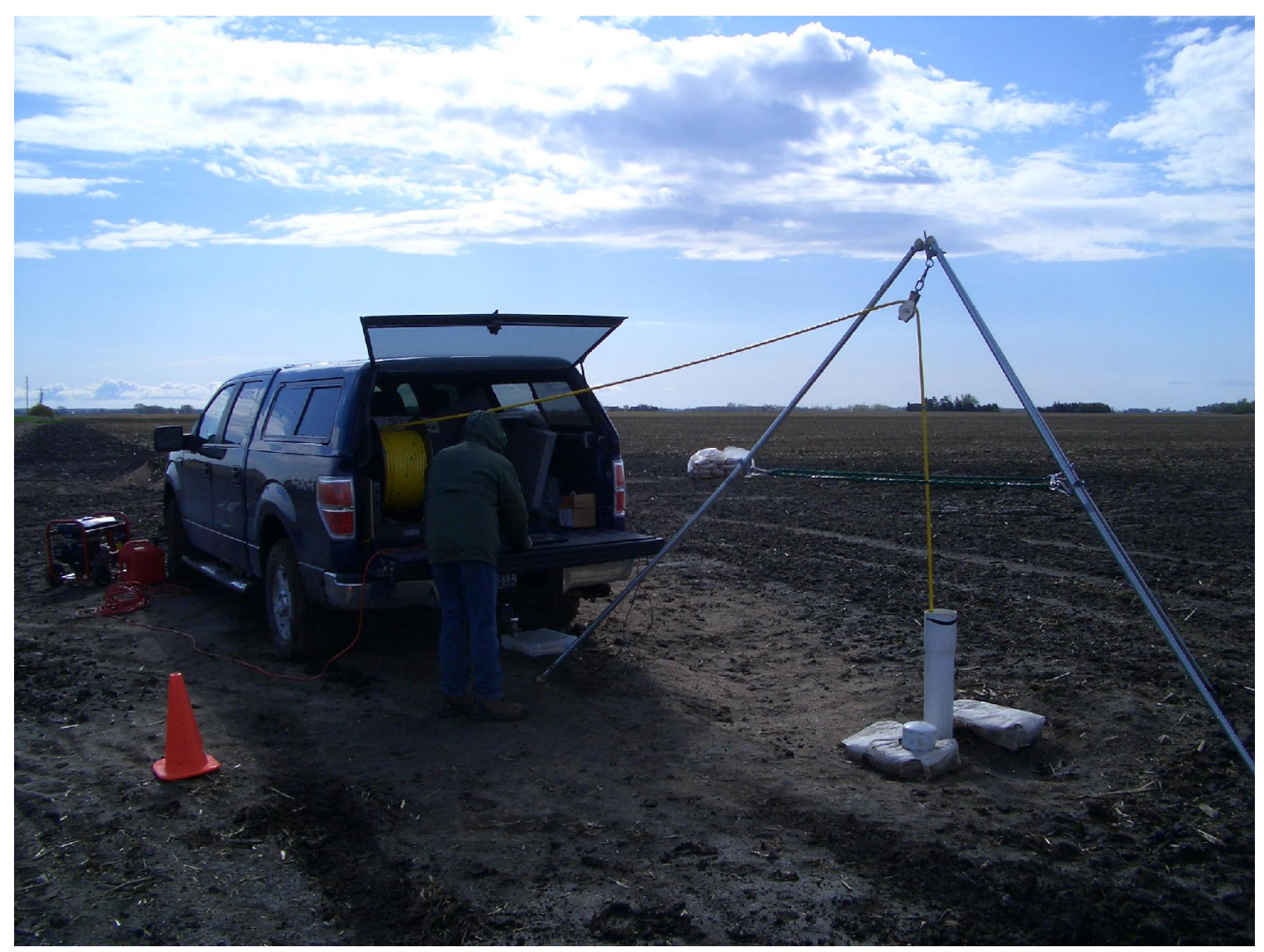

Figure 8: Borehole NMR instrument at site 58b. Lexington NE, April 24, 2010.

The data on April 8 were acquired using the following sequence parameters:

Cable length $=470$ feet

Echo spacing $=2.5 \mathrm{~ms}$

N_stack $=50$ per depth interval

10 minutes per depth interval

$0.5 \mathrm{~m}$ intervals

logging rate $=3 \mathrm{~m} /$ hour

total logging time $=40$ hours

The complete NMR log of the site $58 \mathrm{~b}$ borehole is shown in Figure 9, and the corresponding spin echo records are shown in Figure 10. These are consistent with all available information on the borehole. In particular, flowmeter measurements show a doubling of flow between $31 \mathrm{~m}$ and $29 \mathrm{~m}$, just where a maximum in mobile water content is indicated in the NMR $\log$. 


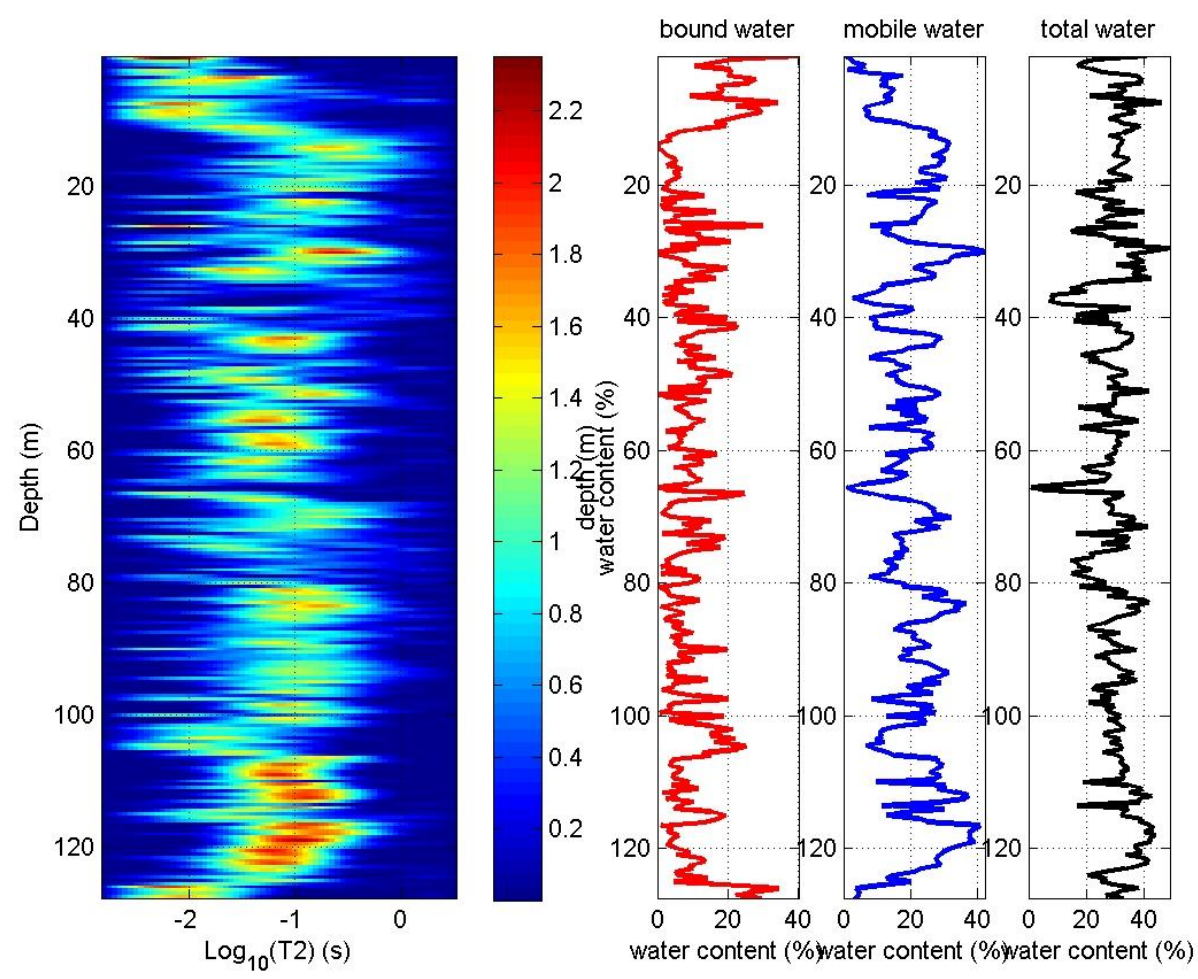

Figure 9: Complete NMR log of borehole at site 58b, vertical resolution $=0.5 \mathrm{~m}$.

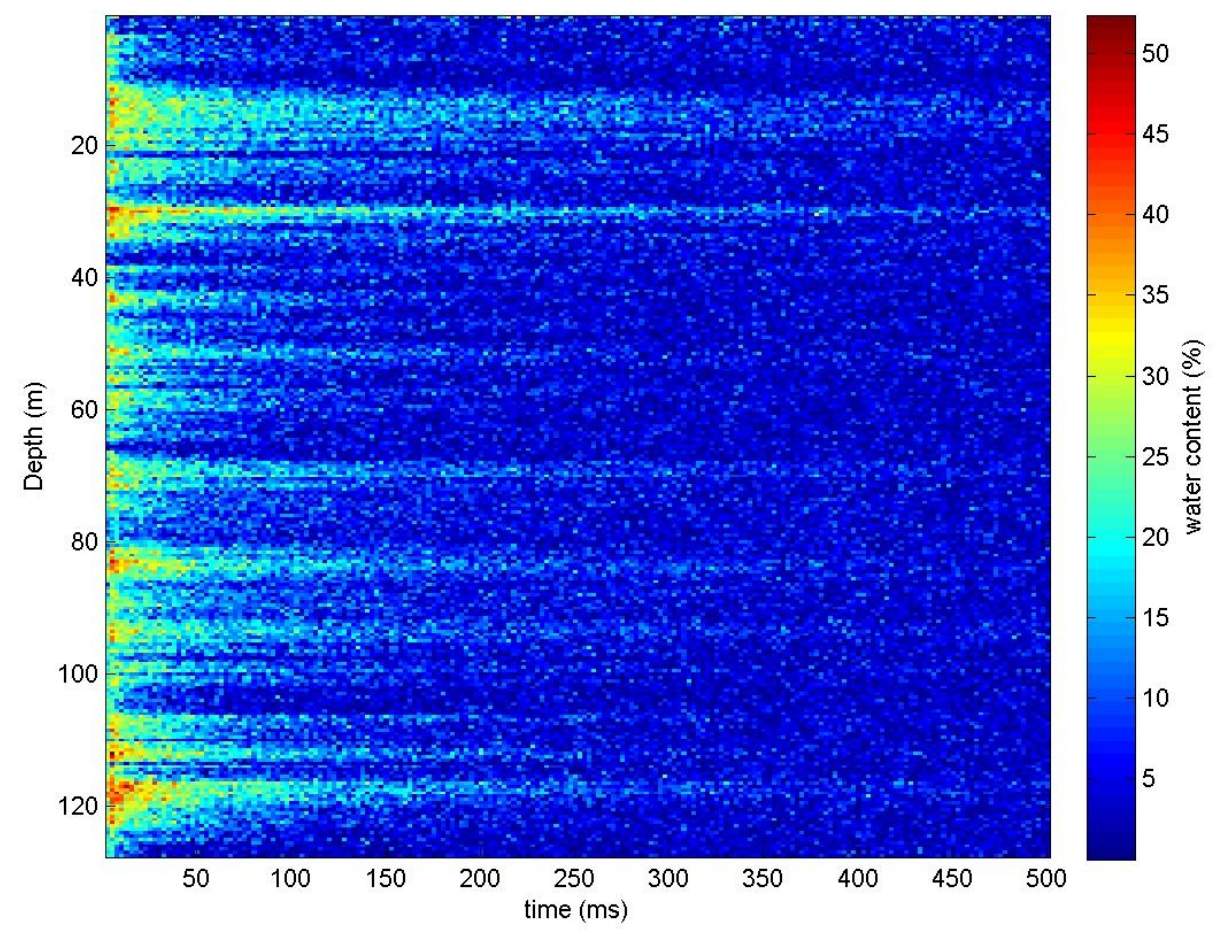

Figure 10: Complete spin echo record for borehole at site 58b. 
We provided our NMR log results from Site $58 \mathrm{~b}$ to Stanford University, who are also evaluating the Schlumberger borehole NMR data from this well and comparing it to surface NMR data. Researchers at Stanford and Schlumberger were reportedly very impressed with our results, as they match the Schlumberger log very closely, and show several potential improvements over the Schlumberger data:

- $\quad$ Spatial Resolution: Vista Clara depth resolution $=0.5 \mathrm{~m}$, compared to $2.5 \mathrm{~m}$ for the Schlumberger NMR log data.

- Ability to log in the top 10m: The Vista Clara log covers the entire borehole, from the surface to the bottom. Schlumberger were not able to log anything in the top 10m due to the length of the Schlumberger tool.

- Avoidance of voids and drilling artifacts: The Vista Clara tool with its 15" diameter sensitive region showed no signs of detecting water in the borehole or in the disturbed zone.

- COST: The Vista Clara NMR log was obtained at a cost of a small fraction of what Schlumberger was paid to log the same well.

\section{Rifle Colorado: April 16 - 17, 2010.}

Our cooperator at the Rifle CO test site was the Lawrence Berkeley National Laboratory. Many thanks to Ken Williams for facilitating these field tests at the Rifle CO DoE test site, for helping with the data collection while we were in the field, and for his general hospitality. Thanks also to Andrew Fitzpatrick from the Australian research organization CSIRO, for helping with the data collection at the Rifle site.

The test site was the DoE research site in Rifle CO, adjacent to the Colorado River. We performed shallow borehole NMR logging in two well-characterized boreholes, with somewhat different lithology and hydrology.

On April 16 we logged the borehole labeled U02, which was situated close to the work trailer on the site, as shown in Figure 11. This was a 4" diameter PVC cased borehole, with a loggable depth of $6 \mathrm{~m}$. The standing water level in the well was $3.5 \mathrm{~m}$. Drilling core material, arranged on the ground nearby, indicated cobbles sand and silt (see Figure 12). The data on April 16 in borehole U02 were acquired using the following sequence parameters:

Cable length $=100$ feet

Echo spacing $=2.5 \mathrm{~ms}$

$\operatorname{Tr}=7 \mathrm{~s}$

N_stack $=100$ per depth interval

16 minutes per depth interval

$0.5 \mathrm{~m}$ intervals

logging rate $=2.0 \mathrm{~m} /$ hour

total logging time $=3.5$ hours 


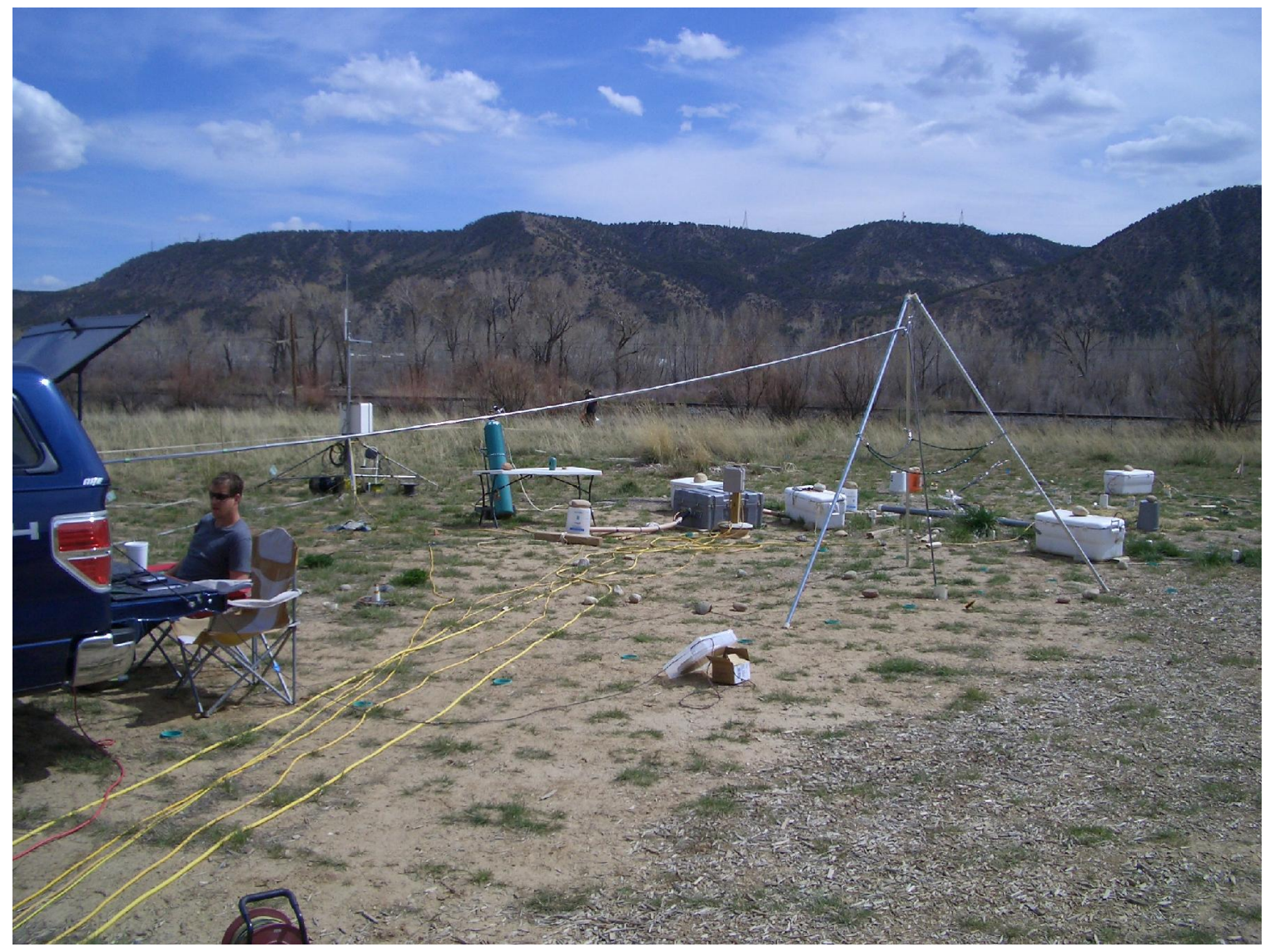

Figure 11: NMR logging of borehole \#U02, on April 16, 2010. Note the proximity of other measurement instrumentation and power lines.

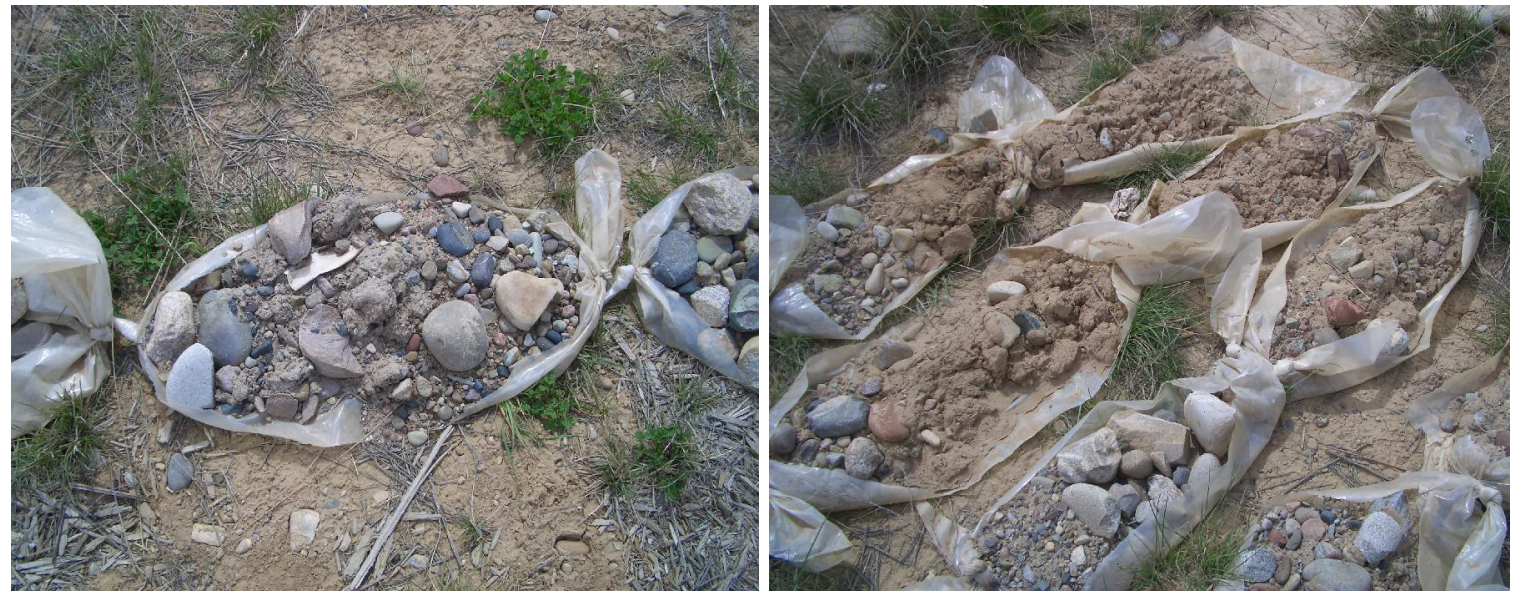

Figure 12: Drilling samples arranged on the ground in the vicinity of borehole U02.

The NMR log of well U02 indicates relatively low water content throughout, which is consistent with poorly-sorted, cobble-dominated sediments. Significant quantities of large pore water only appear in the lowest two measurements $(5.5 \mathrm{~m}$ and $6.0 \mathrm{~m})$. The NMR log also indicates two layers with significant water retention in the unsaturated zone: $0.5 \mathrm{~m}-$ $1.0 \mathrm{~m}$, and again at $2.0 \mathrm{~m}$. These indicate water held in small pore spaces, between fine grains (e.g. silt and clay). 

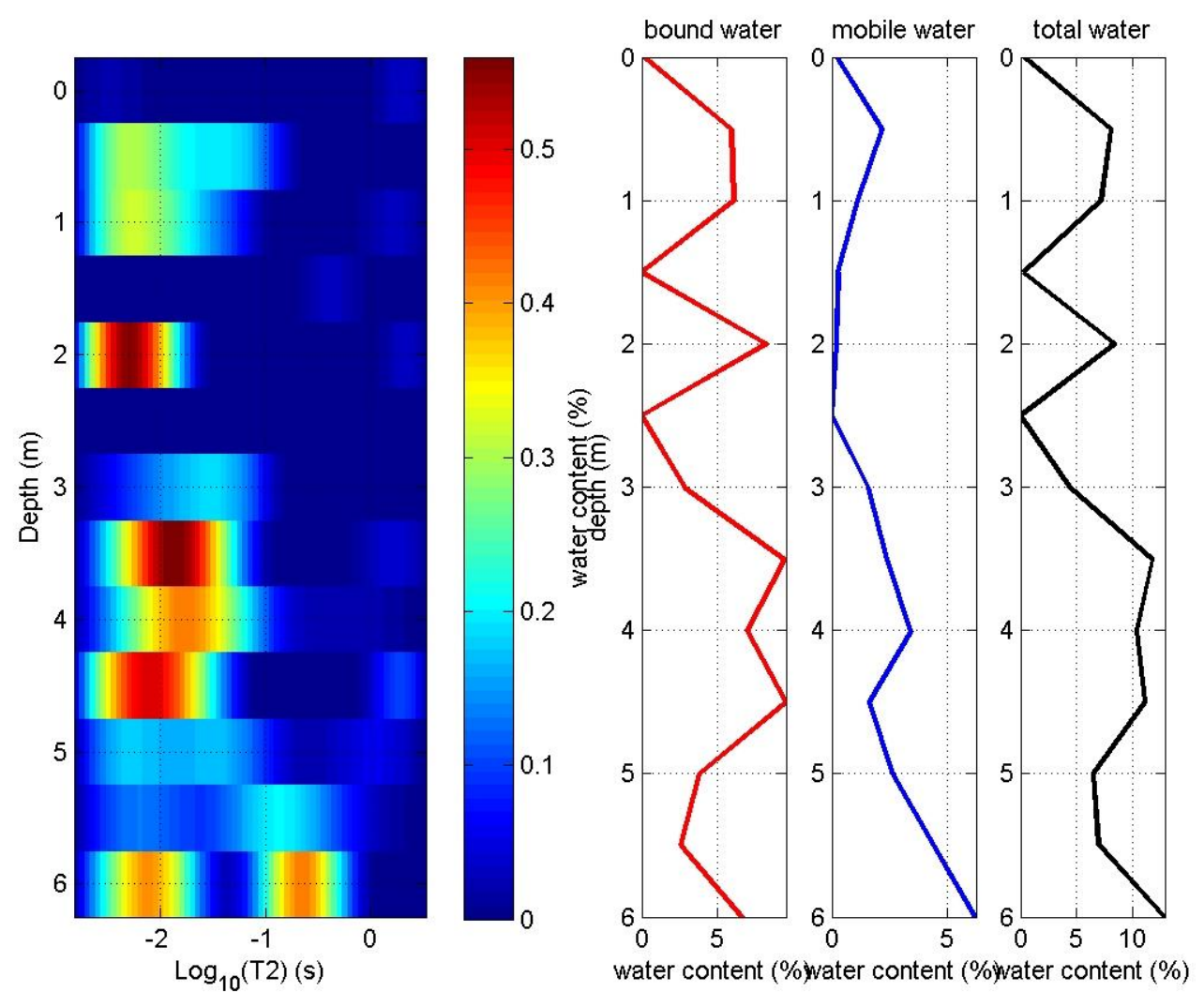

Figure 13: Borehole NMR log of well U02, April 16, 2010.

Due to the low water content, the relatively high noise, and the predominance of short NMR signals which are subject to greater fitting errors, we conducted additional measurements with noise only (transmitter turned off) to determine the statistical variation of derived water contents due to noise alone. The results from three "noise only" measurements, shown in Table 1, indicate that the variation in derived water content due to noise is less than or equal to $2.5 \%$.

\begin{tabular}{|c|c|c|c|c|}
\hline $\begin{array}{c}\text { Measurement } \\
\text { Noise Only }\end{array}$ & $\begin{array}{c}\text { Measurement } \\
\text { depth }(\mathrm{m})\end{array}$ & $\begin{array}{c}\text { Bound Water } \\
\text { Content }\end{array}$ & $\begin{array}{c}\text { Mobile Water } \\
\text { Content }\end{array}$ & $\begin{array}{c}\text { Total Water } \\
\text { Content }\end{array}$ \\
\hline 1 & 0.0 & $0.8 \%$ & $0.5 \%$ & $1.3 \%$ \\
\hline 2 & 1.0 & $1.9 \%$ & $0.0 \%$ & $1.9 \%$ \\
\hline 3 & 1.0 & $0.0 \%$ & $0.0 \%$ & $0.0 \%$ \\
\hline 4 & 6.0 & $0.0 \%$ & $0.0 \%$ & $0.0 \%$ \\
\hline Mean Values & & $0.675 \%$ & $0.125 \%$ & $0.8 \%$ \\
\hline
\end{tabular}

Table 1: Statistical variation of derived water content due to noise only at borehole U02.

We also performed three independent NMR acquisitions at the depth of $6.0 \mathrm{~m}$, and compared the three results for consistency. The three acquisitions were performed at different times during the day, and the probe had been raised and lowered between each 
of these measurements and presumably incurred a change in azimuth and lateral offset location within the well.

\begin{tabular}{|l|c|c|c|c|}
\hline $\begin{array}{l}\text { NMR Measurement } \\
\text { at 6.0m }\end{array}$ & $\operatorname{Tr}(\mathrm{s})$ & $\begin{array}{l}\text { Bound Water } \\
\text { Content }\end{array}$ & $\begin{array}{l}\text { Mobile Water } \\
\text { Content }\end{array}$ & $\begin{array}{l}\text { Total Water } \\
\text { Content }\end{array}$ \\
\hline Original & $5 \mathrm{~s}$ & $6.6 \%$ & $6.2 \%$ & $12.8 \%$ \\
\hline Repeat \#1 & $5 \mathrm{~s}$ & $11.6 \%$ & $6.6 \%$ & $18.2 \%$ \\
\hline Repeat \#2 & $3 \mathrm{~s}$ & $3.0 \%$ & $6.0 \%$ & $9.0 \%$ \\
\hline
\end{tabular}

Table 2: Variation in derived water content, as a function of lateral position and azimuth angle of probe in the borehole \#U02. Noise may also be contributing to the variance of bound water content.

The results shown in Table 2 indicate significant variance in the derived bound water content for the 3 independent measurements. Presumably this is due to the change in azimuth angle and lateral offset of the probe between each measurement. It is noted that the sensitive zone of the probe is not uniform in azimuth, and any change in lateral offset and/or azimuth will result in the cylindrical sensitive zone detecting water in a different sample of the formation. Hence it appears that the variance in derived water content is a function of the heterogeneity of the formation, more so than the effect of noise in the measurement.

On April 17 we logged the borehole labeled LR-01, which was situated towards the Western edge of the site, as shown in Figure 14. This was a 4" diameter PVC cased borehole, with a loggable depth of $7.25 \mathrm{~m}$. This well was selected because it had a known channel of well-sorted sand at approximately $6.0 \mathrm{~m}$. The standing water level in the well was $4.6 \mathrm{~m}$.

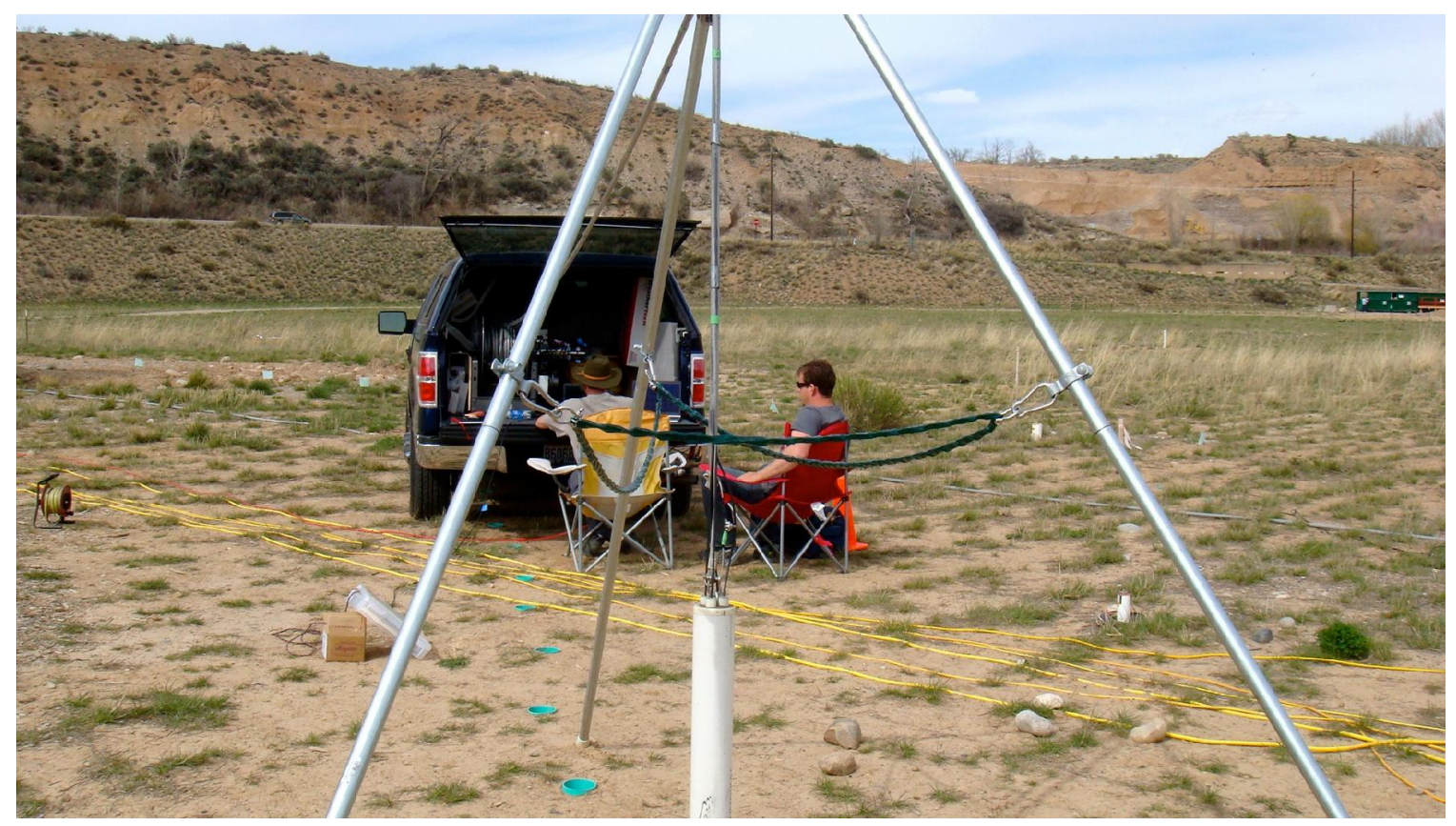

Figure 14: Logging borehole LR-01, April 17, 2010. 
The data on April 17 in borehole U02 were acquired using the following sequence parameters:

Cable length $=100$ feet

Echo spacing $=2.5 \mathrm{~ms}$

$\operatorname{Tr}=5 \mathrm{~s}$

N_stack $=200$ per depth interval

30 minutes per depth interval

$0.5 \mathrm{~m}$ intervals

logging rate $=1.0 \mathrm{~m} /$ hour

total logging time $=4.5$ hours

The NMR log from well LR-01 is shown in Figure 15, and the spin echo data vs. depth is shown in Figure 16. The sand channel is clearly evident by the peak in long relaxing (mobile) water content at $6 \mathrm{~m}$. There is also an apparent zone of high bound water content at $3 \mathrm{~m}$, which is above the water table. This indicates a low permeability zone which might act as a control for contaminant transport in the vadose zone. Unfortunately thunderstorms in the area interrupted our data collection and we were not able to log the top $2.5 \mathrm{~m}$ of the vadose zone on this day.

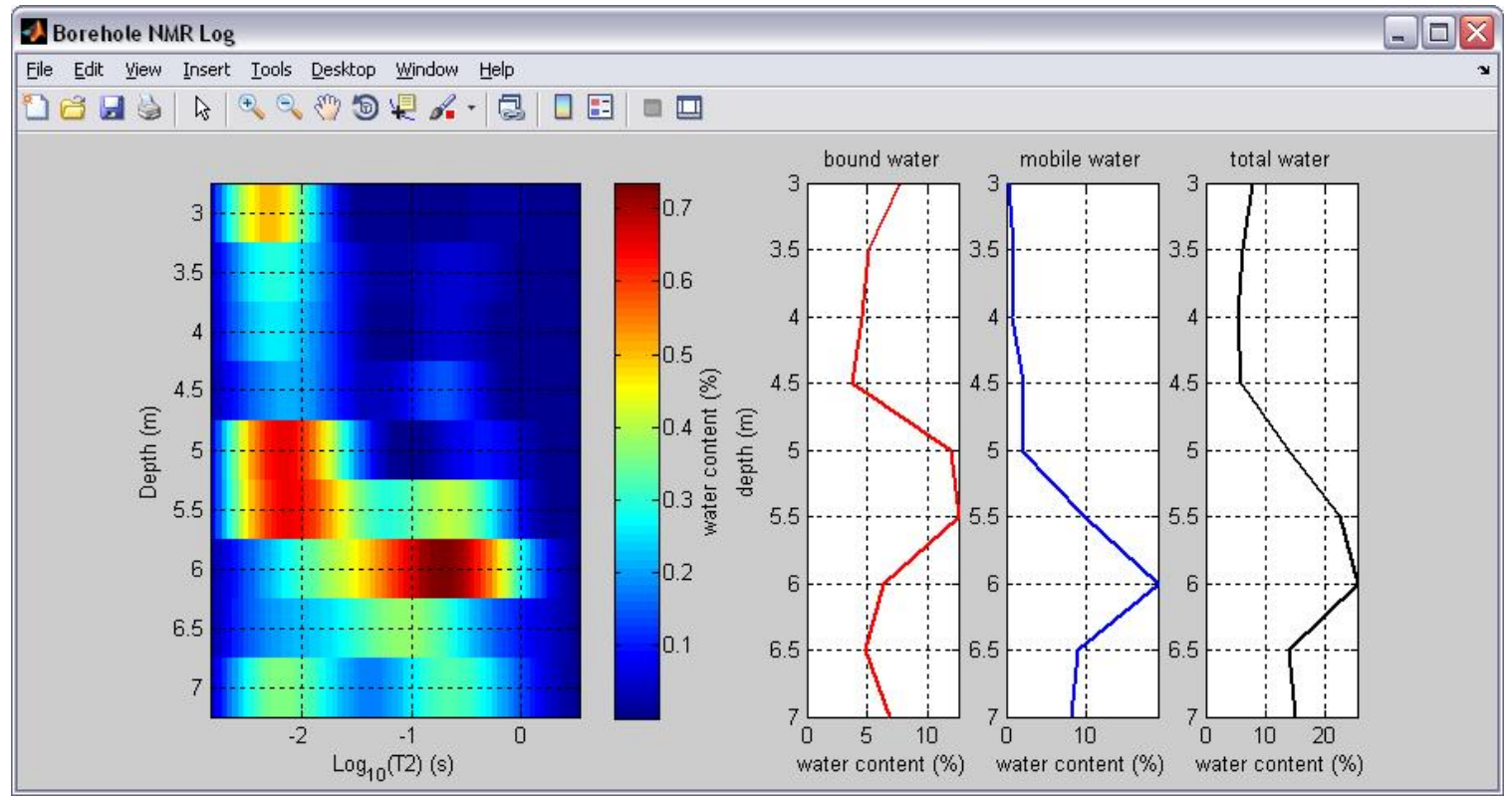

Figure 15: Borehole NMR log of well LR-01, April 17, 2010. 


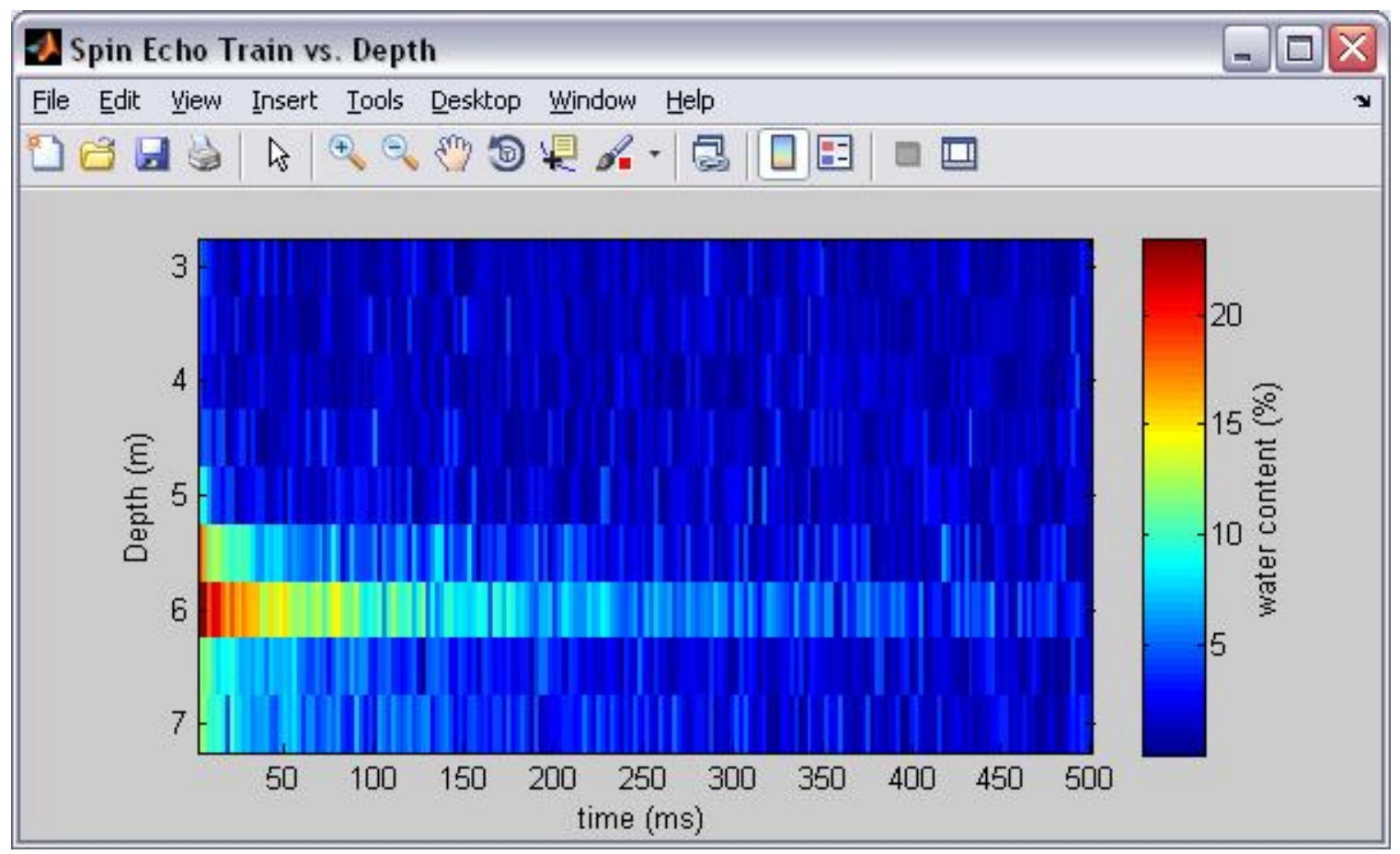

Figure 16: Spin echo train vs. depth at well LR-01, April 17, 2010.

\section{Lawrence Kansas: April 19 - 22, 2010.}

Our cooperator at the Lawrence KS test site was the Kansas Geological Survey (KGS), affiliated with the University of Kansas. Many thanks to Jim Butler for facilitating these field tests at the GEMS test site, and to his colleagues at KGS for assisting with the data collection while we were in the field.

The test site was the Geohydrologic Experimental and Monitoring Site (GEMS) of the KGS near Lawrence Kansas. A photo of our NMR logging instrument at the site is shown in Figure 17. We logged two, 4" diameter PVC cased boreholes at the site, each from the surface to the maximum loggable depth of $21 \mathrm{~m}$. The standing water level in the wells was 4.2m below ground surface. On April 19 - 20, we logged borehole 4S using the following sequence parameters:

Cable length $=100$ feet

Echo spacing $=2.5 \mathrm{~ms}$

$\operatorname{Tr}=6 \mathrm{~s}$

N_stack $=100$ per depth interval

20 minutes per depth interval

$0.5 \mathrm{~m}$ intervals

logging rate $=1.5 \mathrm{~m} /$ hour

total logging time $=13.5$ hours 


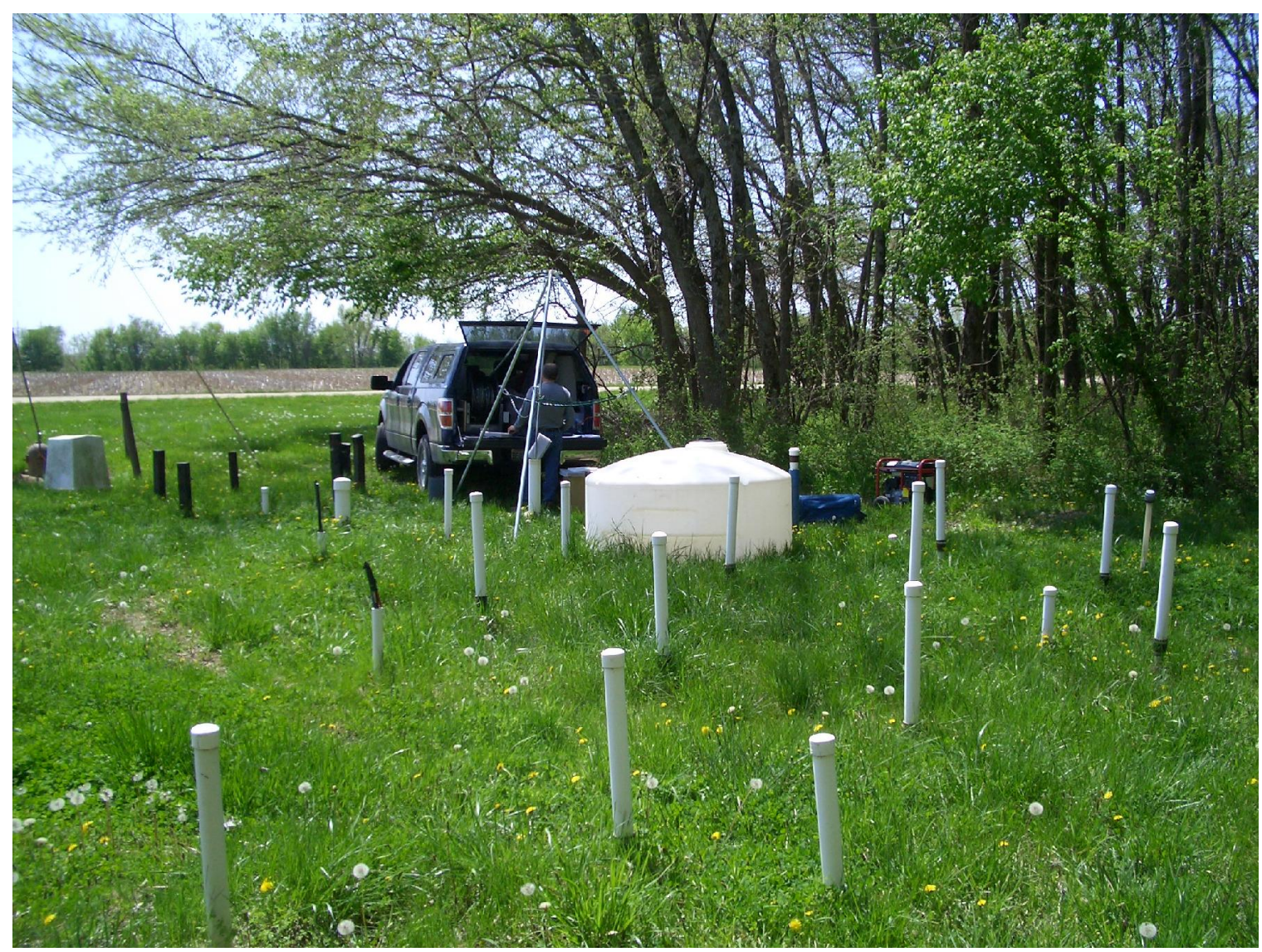

Figure 17: Vista Clara employee Igor Frid monitoring an NMR logging experiment in GEMS well \#4S, April 192010.

The resultant NMR log of borehole $4 \mathrm{~S}$ is shown in Figure 18, and the spin echo data vs. depth are shown in Figure 19. The borehole log shows a dramatic transition at around $11 \mathrm{~m}$, between the saturated silt and clay (above $11 \mathrm{~m}$ ) and well-sorted sand below $11 \mathrm{~m}$. The log also indicates significant amounts and variations in water content in the unsaturated zone (above $4 \mathrm{~m}$ ). The log also indicates a curious presence of long T2 water between $2 \mathrm{~m}$ and $5 \mathrm{~m}$, apparently in the unsaturated zone. After lengthy discussion with KGS it is thought that there could be significant quantities of water held in large pore spaces in the grout that surrounds the top $5 \mathrm{~m}$ of the well casing. The test site had been inundated with rain approximately a week before our data collection, and the grout at the surface showed large cracks and fissures related to repeated wetting and drying.

Jim Butler of the Kansas Geological Survey compared the NMR log of this well to previous measurements of hydraulic conductivity vs. depth. Figure 20 shows his plot of NMR-derived bound water content vs. hydraulic conductivity in the well, and the comparison shows that the two plots are inversely related. This is not unexpected, as increased bound water content indicates increased concentration of small pore water (finer material) and hence expected lower permeability. 
Borehole NMR Log

File Edit View Insert Iools Desktop window Help

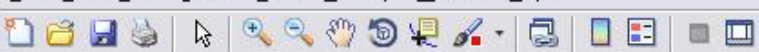

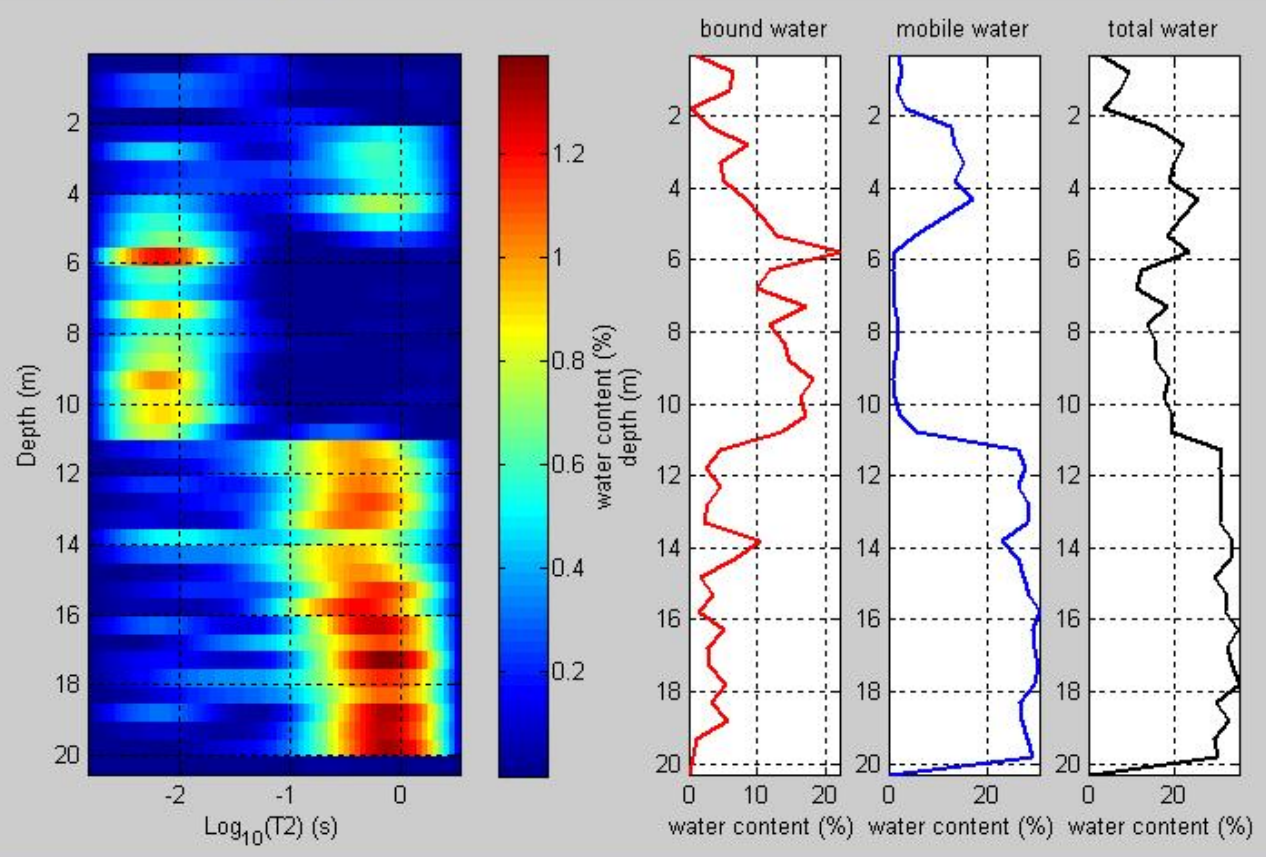

Figure 18: Borehole NMR log, GEMS well \#4S, April 192010.

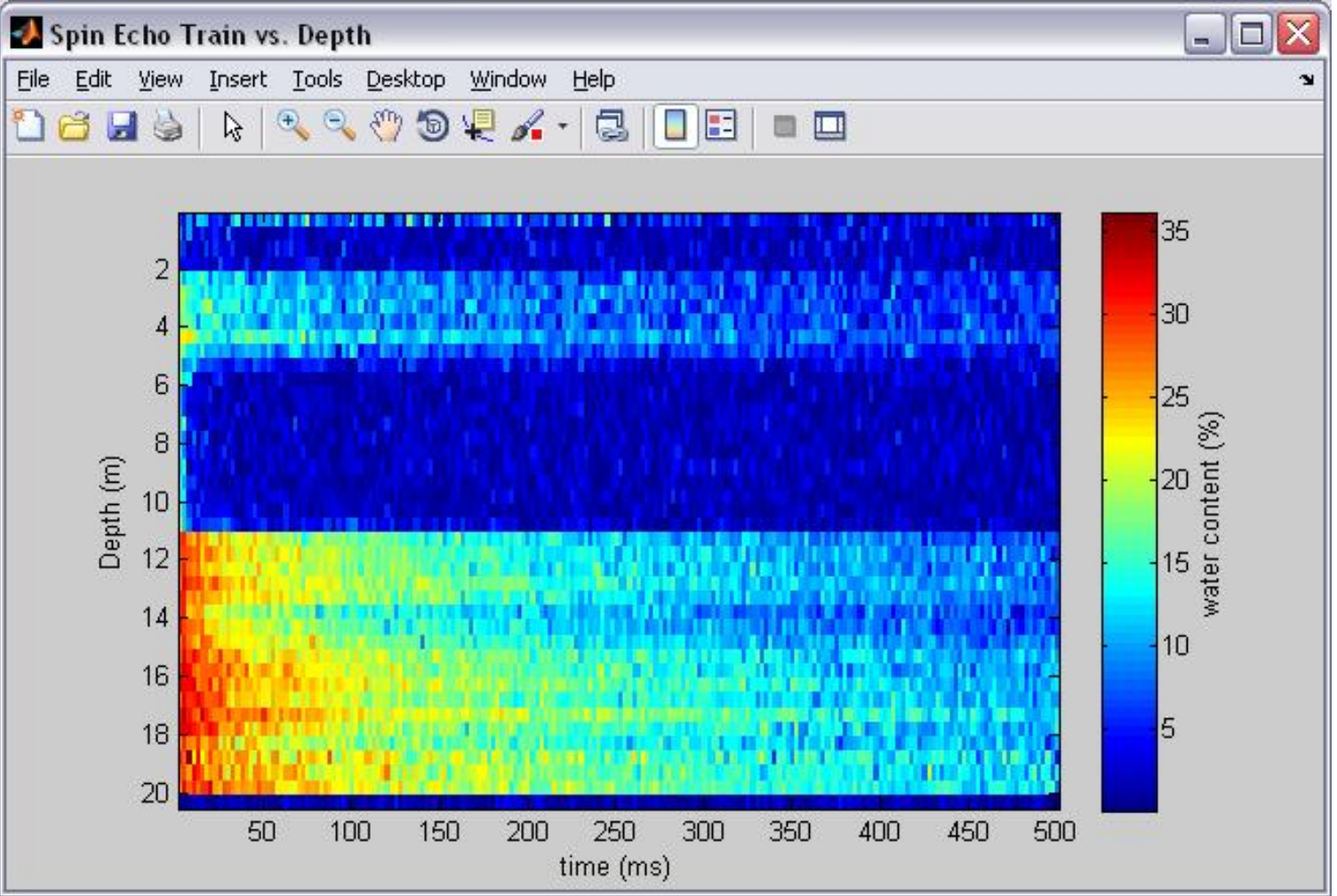

Figure 19: Spin echo train vs. depth, GEMS well \#4N, April 19, 2010. 


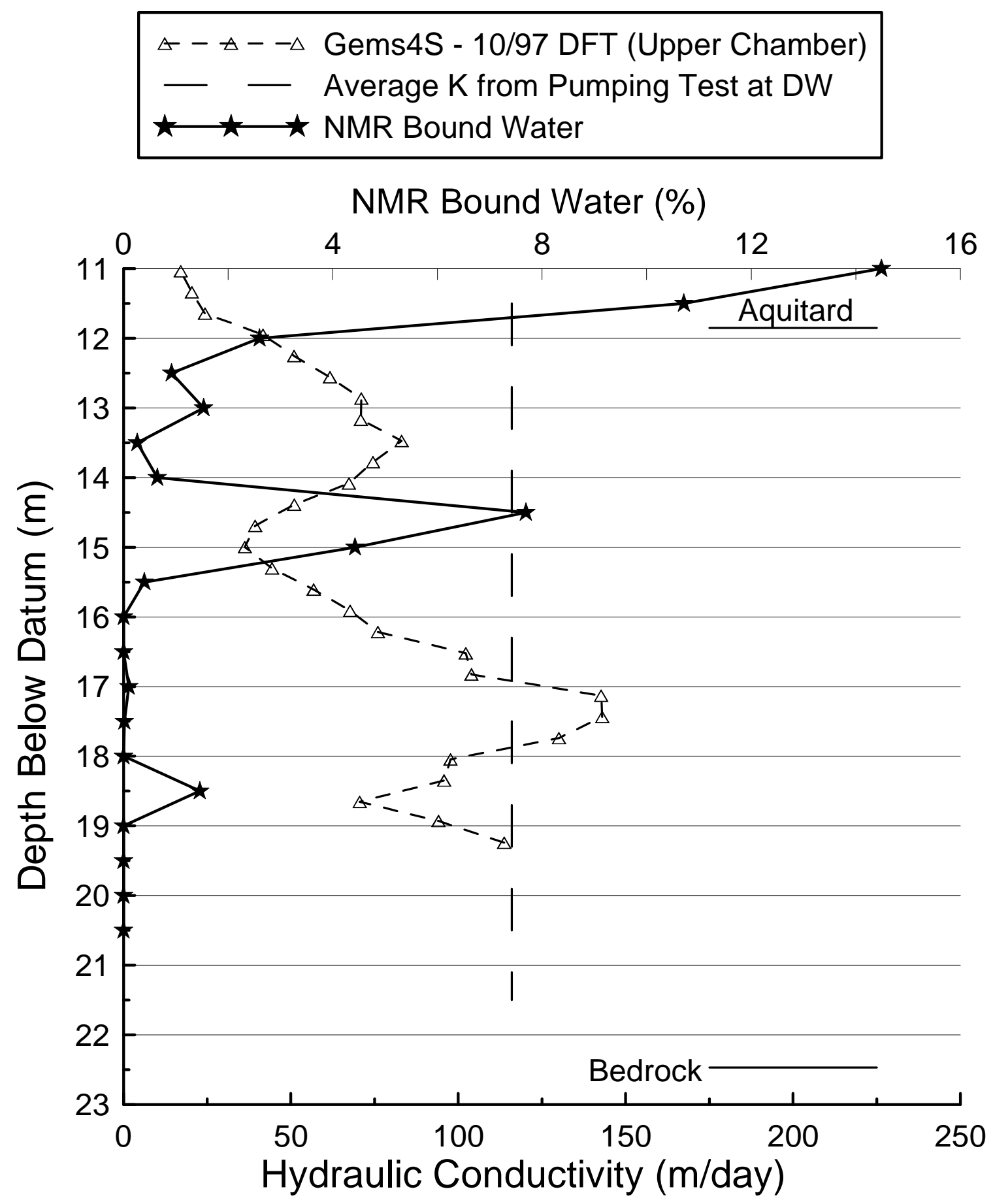

Figure 20: Plots of NMR-derived bound water content and hydraulic-test-based measurement of hydraulic conductivity vs. depth, at borehole 4S, GEMS, Lawrence KS.

On April 21, we logged borehole 4N using the following sequence parameters:

Cable length $=100$ feet

Echo spacing $=2.5 \mathrm{~ms}$

$\operatorname{Tr}=6 \mathrm{~s}$ 
N_stack $=100$ per depth interval (top $14 \mathrm{~m}$ ), 50 per depth interval (below $14 \mathrm{~m}$ ) 20 minutes per depth interval (above $14 \mathrm{~m}$ ), 10 minutes per interval below $14 \mathrm{~m}$ $0.5 \mathrm{~m}$ intervals

logging rate $=1.5 \mathrm{~m} /$ hour $-3.0 \mathrm{~m} /$ hour

total logging time $=11.5$ hours

The resultant NMR log of borehole $4 \mathrm{~N}$ is shown in Figure 21. This borehole log shows a more gradual transition between the saturated silt and clay (above $11 \mathrm{~m}$ ) to the well-sorted sand below $11 \mathrm{~m}$. Jim Butler indicated that this is consistent with KGS existing data on this borehole. The log also again indicates significant amounts and variations in water content in the unsaturated zone (above $5 \mathrm{~m}$ ). The log also indicates the same curious presence of long T2 water between $2 \mathrm{~m}$ and $5 \mathrm{~m}$, apparently in the unsaturated zone.



Figure 21: Borehole NMR log, GEMS well \#4S, April 192010.

\section{Boise ID: April 28 - 29, 2010.}

Our cooperator at the Boise ID test site was Boise State University. Many thanks to Warren Barrash for facilitating these field tests and for assisting us in the field.

The test site was the Boise Hydrogeophysical Research Site, operated by Boise State University adjacent to the Boise River near Boise Idaho. A photo of Warren Barrash with our NMR logging instrument at the site is shown in Figure 22. We logged a single, 4" diameter PVC cased borehole at the site (well \# C4), from 3m below the surface to the 
maximum loggable depth of $19 \mathrm{~m}$. The standing water level in the well was $2 \mathrm{~m}$ below ground surface.

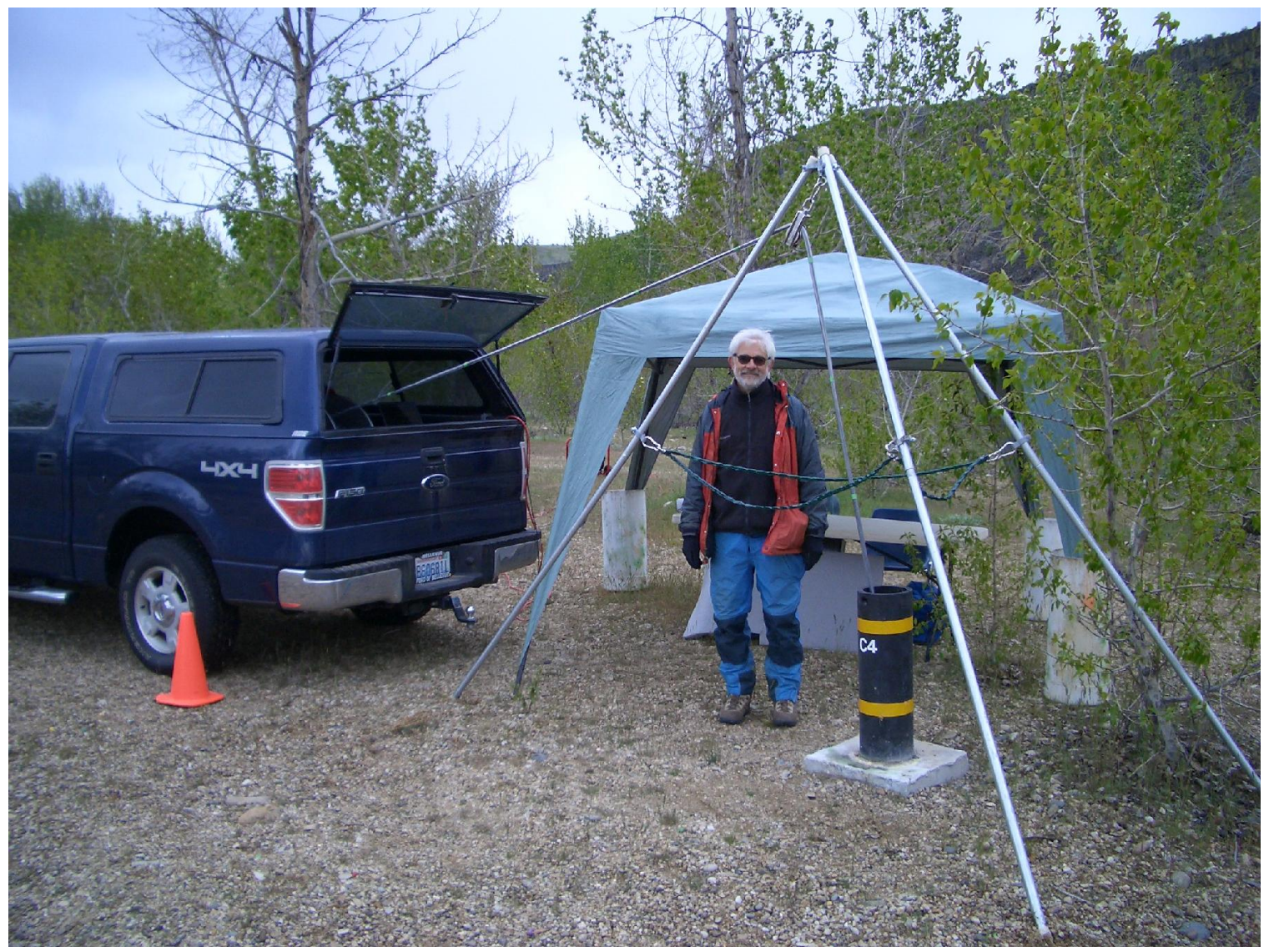

Figure 22: Dr. Warren Barrash and our borehole NMR instrumentation at the BHRS test site on April 29, 2010.

On April 28-29, we logged borehole C4 using the following sequence parameters:

Cable length $=100$ feet

Echo spacing $=2.5 \mathrm{~ms}$

$\operatorname{Tr}=6 \mathrm{~s}$

N_stack $=75$ per depth interval

15 minutes per depth interval

$0.5 \mathrm{~m}$ intervals

logging rate $=2.0 \mathrm{~m} /$ hour

total logging time $=8.5$ hours

The resulting borehole NMR log is shown in Figure 23, along with graphs of the neutronderived porosity and core-derived cobble/gravel/matrix fractions that were cut and pasted from a BHRS publication. The sand channel at $2.5 \mathrm{~m}$ to $4 \mathrm{~m}$ produces a maximum NMR derived water content of around $45 \%$. This huge number is consistent with the neutron- 
derived porosity, and according to Warren Barrash, is reasonable for this sort of high energy sand deposit.

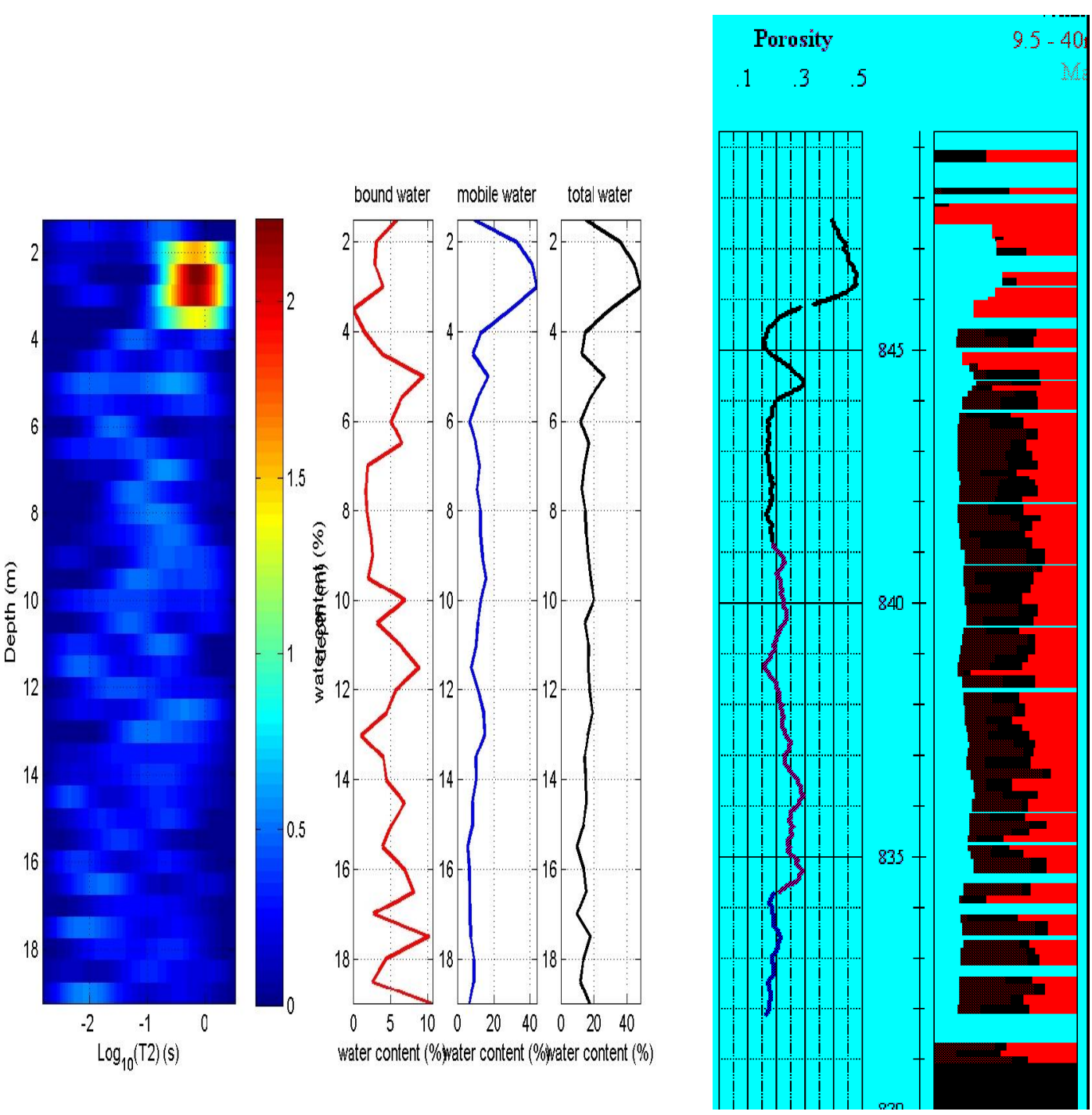

Figure 23: Left: borehole NMR log of well C4. Right: neutron-derived porosity log of Well C4 plus Cobble/Gravel/Matrix content vs. depth. Note: these two plots were aligned using the "eyeball method".

One additional note from the Boise tests, at the conclusion of the $2^{\text {nd }}$ day of logging, when we lifted the NMR probe out of the well it had significant amounts of ferrous particles clinging to it. Photos of this are shown in Figure 24. The source of the iron-rich particles is not clear, they might be from basalt or other minerals in the formation, or perhaps are iron filings generated by the drilling process. 


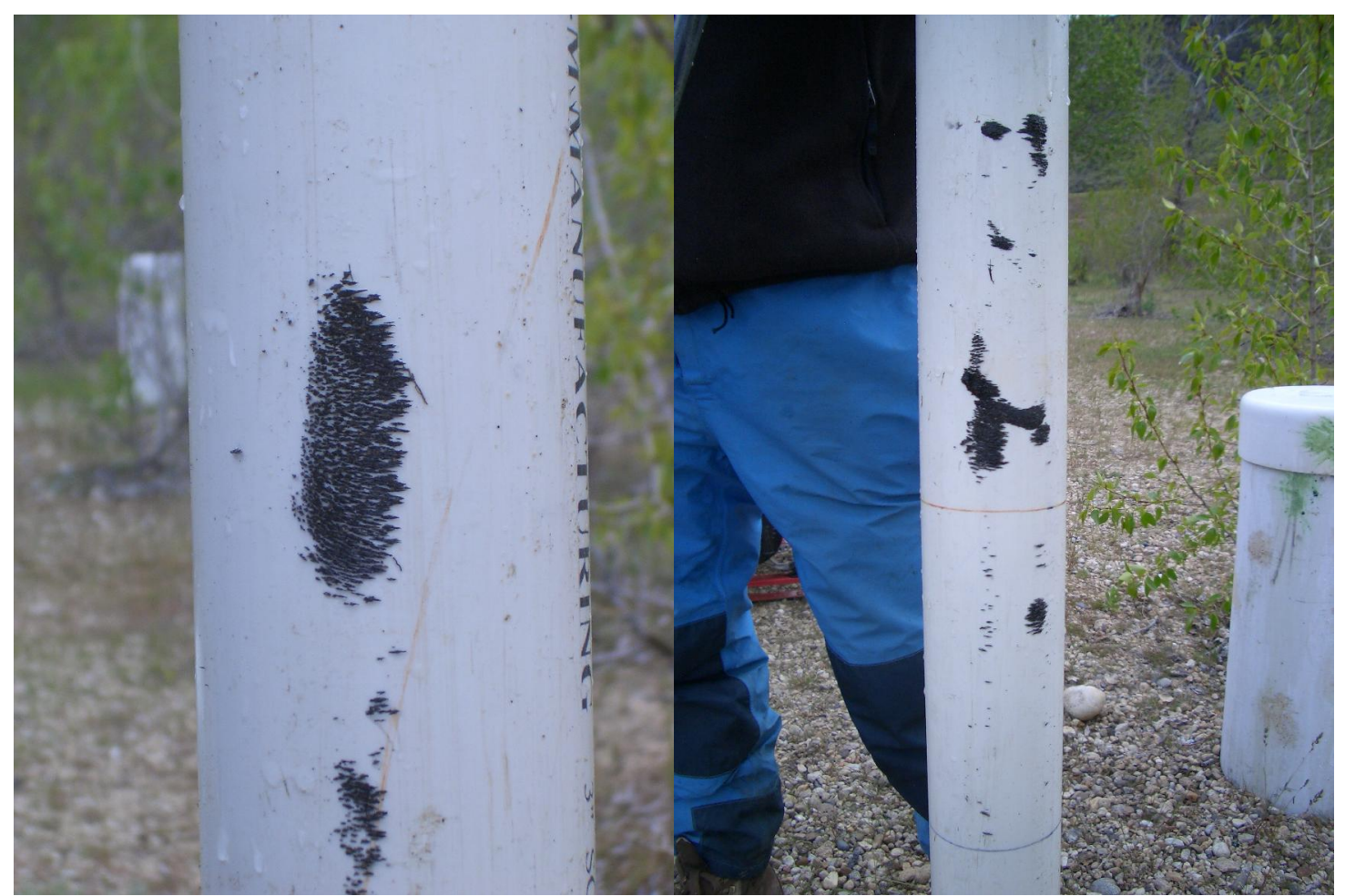

Figure 24: Iron-rich particles clinging to the NMR probe after raising it from the well in Boise ID.

\section{Connecticut and Massachusetts: May 24-28, 2010.}

Our cooperator for these field tests was John Lane of the USGS. Many thanks to the USGS personnel from Storrs CT, and Cape Cod MA, for their help with data collection, and for funding the equipment mobilization and travel costs for these tests.

The Haddam Meadow test site is situated in a large public park adjacent to the Connecticut River, in East Haddam CT. Photos of the borehole NMR instrumentation at the site are shown in Figures 25 and 26.

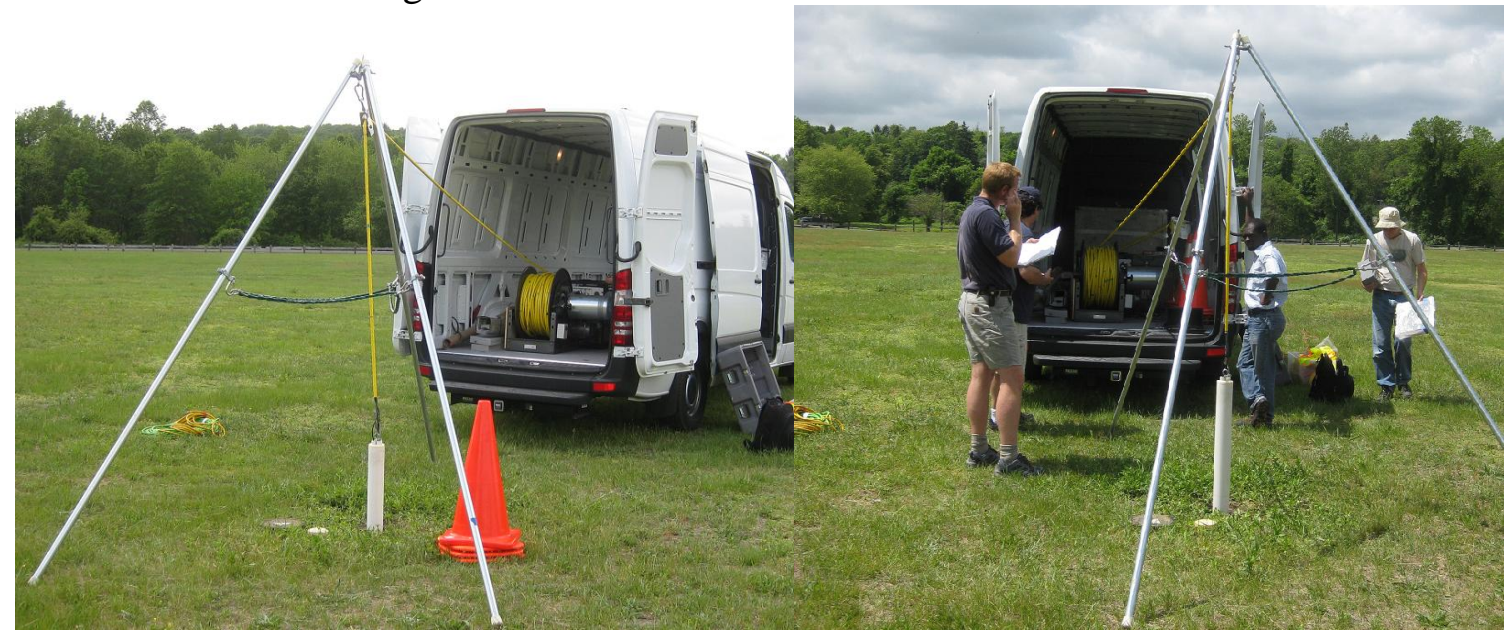

Figure 25: Borehole NMR instrumentation at Haddam Meadows, May 24, 2010. 


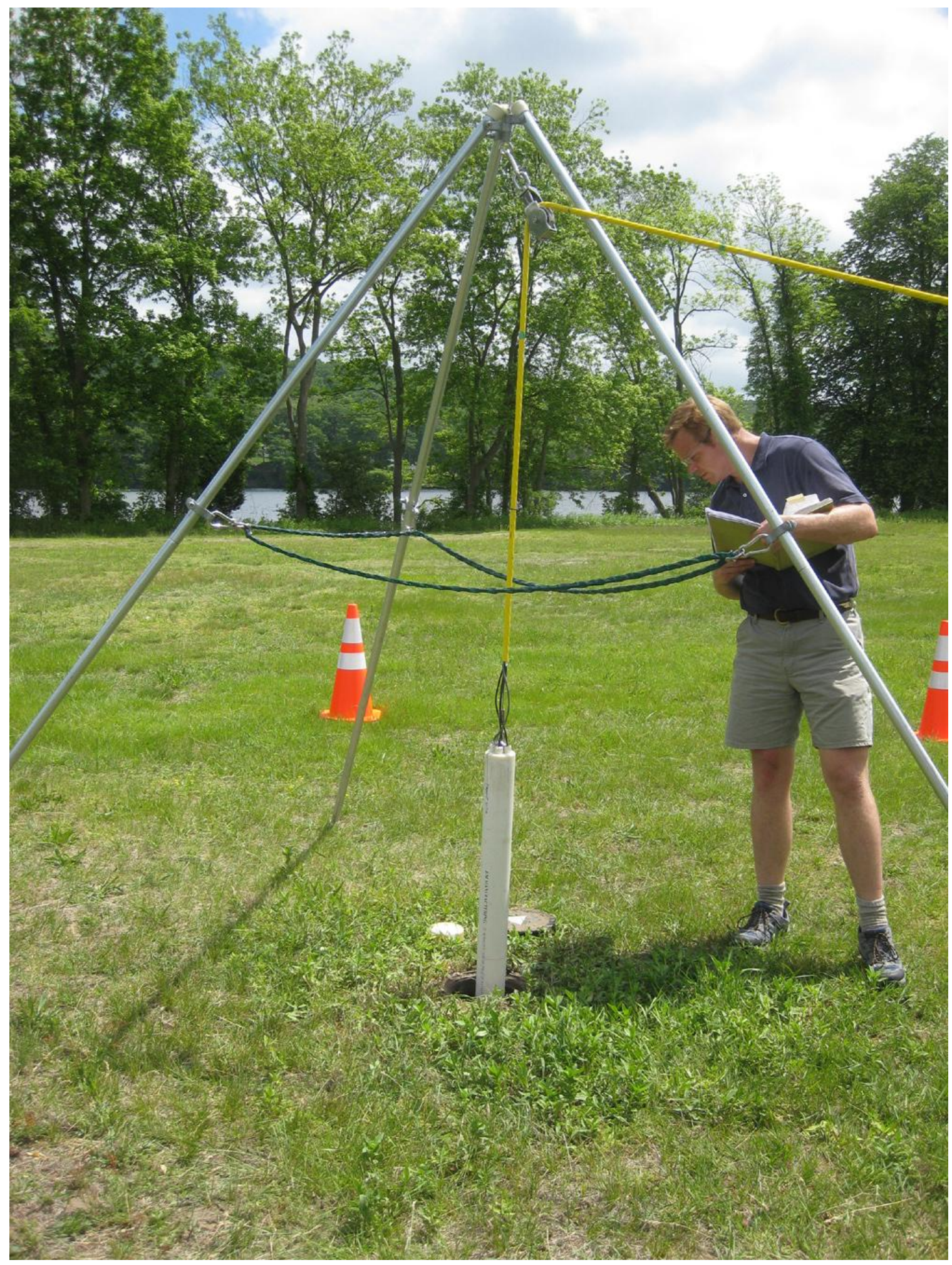

Figure 26: Borehole NMR sensor being lowered into the borehole at Haddam Meadow State Park on May 24, 2010. 
On May 24-25, we logged well \#JL-1 from the surface to its maximum loggable depth of $35 \mathrm{~m}$, using the following sequence parameters:

Cable length $=470$ feet

Echo spacing $=2.5 \mathrm{~ms}$

$\operatorname{Tr}=6 \mathrm{~s}$

N_stack $=50$ per depth interval

10 minutes per depth interval

$0.5 \mathrm{~m}$ intervals

logging rate $=3.0 \mathrm{~m} /$ hour

total logging time $=11.8$ hours

The resulting borehole NMR log is shown in Figure 27. The standing water level in the well was $2.2 \mathrm{~m}$ below ground surface. The USGS have not finished analyzing the data from this test, but they appeared to be satisfied with the result as the data were reported in the field. The zone at approximately $7 \mathrm{~m}$ with very long decay water appears suspicious, and we may be detecting some bulk water in a void created there during the drilling process.
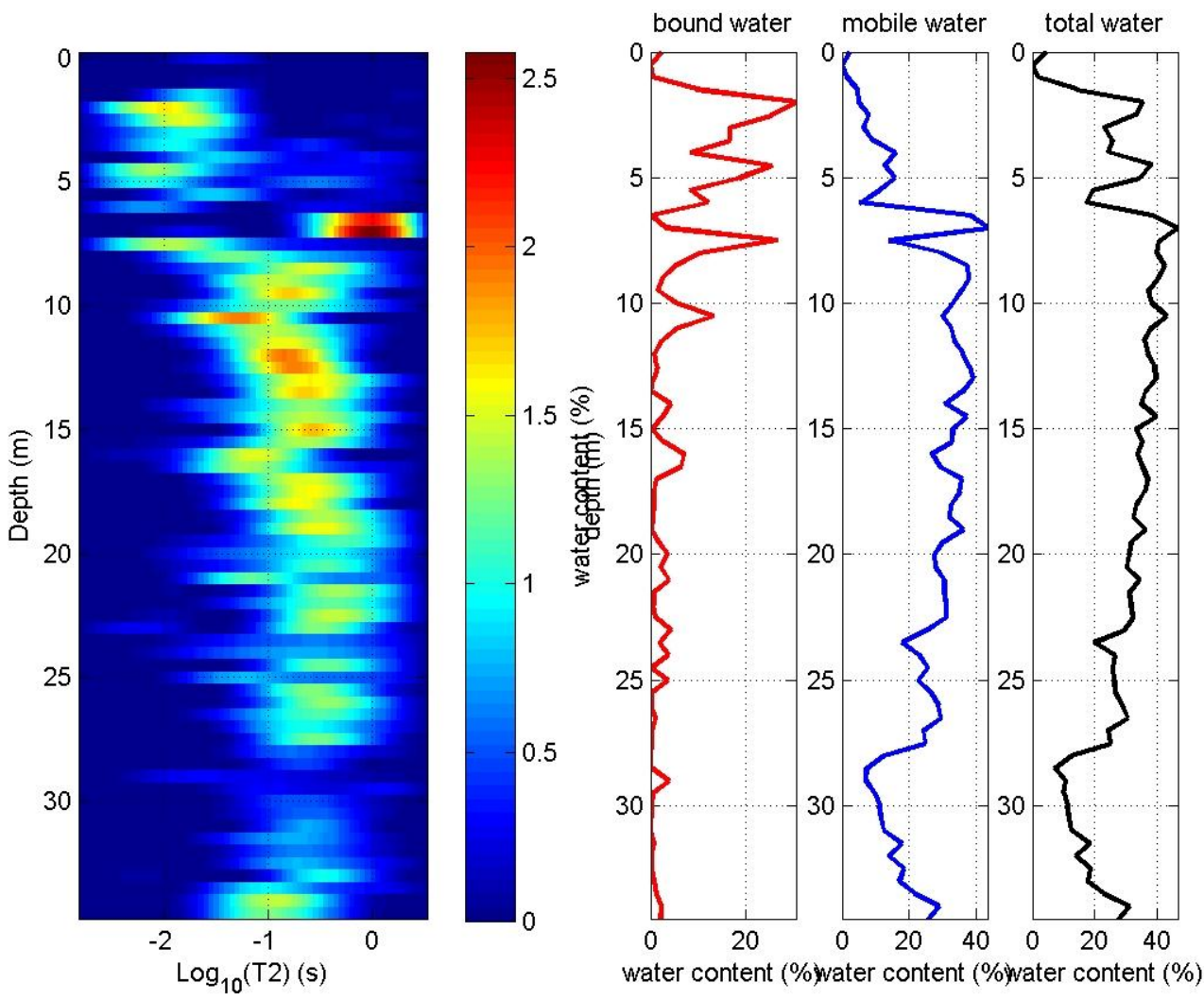

Figure 27: NMR log of well \#JL-1 at Haddam Meadow CT, May 24 - 25, 2010.

We performed noise-only measurements to measure the variance of derived water content due to noise. These measurements used the same acquisition variables that were used in 
the logging data, except the transmitter was turned off. Table 3 lists the derived water content for two noise measurements obtained at the ground surface level and one obtained at the bottom of the well.

\begin{tabular}{|l|c|c|c|c|}
\hline Date & Depth & $\begin{array}{l}\text { Total Water } \\
\text { Content }\end{array}$ & $\begin{array}{l}\text { Bound Water } \\
\text { Content }\end{array}$ & $\begin{array}{l}\text { Mobile Water } \\
\text { Content }\end{array}$ \\
\hline $5 / 24 / 2010$ & $0 \mathrm{~m}$ & $2.04 \%$ & $1.35 \%$ & $0.70 \%$ \\
\hline $5 / 25 / 2010$ & $0 \mathrm{~m}$ & $0.65 \%$ & $0.06 \%$ & $0.58 \%$ \\
\hline $5 / 25 / 2010$ & $34.5 \mathrm{~m}$ & $1.66 \%$ & $1.66 \%$ & $0.00 \%$ \\
\hline Mean values & & $1.45 \%$ & $1.02 \%$ & $0.43 \%$ \\
\hline
\end{tabular}

Table 3: Derived water content for noise-only measurements at Haddam Meadows well JL-1.

We also performed repeatability measurements at Haddam Meadows well JL-1. Four separate logging measurements were performed at the same nominal depth of $10.5 \mathrm{~m}$ in the well. The first measurement was made during the initial logging on May 24, 2010. The second measurement (repeat \#1) was made on the following day, May 25. The third measurement (repeat \#2) was made immediately after repeat \#1, but after raising and lowering the NMR probe and turning it approximately 90 degrees in the well. The fourth measurement (repeat \#3) was made immediately after repeat \#2, without moving the NMR probe.

The results, shown in Table 4, indicate that the derived water content varies significantly as a function of the azimuth angle and lateral position of the sensor in the well, and that random noise causes less variation than changes in sensor orientation and position. This in turn indicates that the primary source of variance in the Haddam Meadow NMR log result is the heterogeneity the formation as it is sampled by the cylindrical NMR sensitivity region.

\begin{tabular}{|l|c|c|c|}
\hline Experiments at depth of $10.5 \mathrm{~m}$ & $\begin{array}{l}\text { Total Water } \\
\text { Content }(\%)\end{array}$ & $\begin{array}{l}\text { Bound Water } \\
\text { Content }(\%)\end{array}$ & $\begin{array}{l}\text { Mobile Water } \\
\text { Content }(\%)\end{array}$ \\
\hline Original log result & 42.6 & 12.9 & 29.7 \\
\hline $1^{\text {st }}$ repeat & 31.0 & 7.2 & 23.8 \\
\hline $2^{\text {nd }}$ repeat (sensor repositioned) & 24.5 & 5.8 & 18.7 \\
\hline $3^{\text {rd }}$ repeat (sensor not moved) & 25.4 & 4.0 & 21.3 \\
\hline
\end{tabular}

Table 4: derived water content for 4 independent NMR measurements at the same nominal depth of 10.5m.

The remaining field tests were conducted in three PVC cased boreholes on the Massachusetts Military Reservation on Cape Cod. The first borehole was a 4" diameter PVC well situated on the side of a road. This well is labeled 03GB1060, and has a maximum loggable depth of 98 meters. We logged this well from a depth of $4 \mathrm{~m}$ to the maximum depth of $98 \mathrm{~m}$ using the following parameters:

Cable length $=470$ feet

Echo spacing $=2.5 \mathrm{~ms}$

$\operatorname{Tr}=6 \mathrm{~s}$

N_stack $=20$ per depth interval 
4 minutes per depth interval

$0.5 \mathrm{~m}$ intervals

logging rate $=7.0 \mathrm{~m} /$ hour

total logging time $=13.5$ hours

The NMR log of well \#03GB1060 is shown in Figure 28. Ongoing contaminant studies at MMR are particularly interested in identifying silt layers that could act as controls on the movement of groundwater and migration of contaminant plumes. The result in Figure 27 indicates at least three such zones: $65 \mathrm{~m}, 70-74 \mathrm{~m}$, and $82-83 \mathrm{~m}$. These are evidenced by an increase in bound water content and decrease in mobile water content over two or more contiguous depth levels. There is a potential clay or silt layer in the unsaturated zone at around $12 \mathrm{~m}$ as well, but the data in this region of the log are noisy (due to overhead powerlines) so a more careful NMR log of the unsaturated zone is warranted.

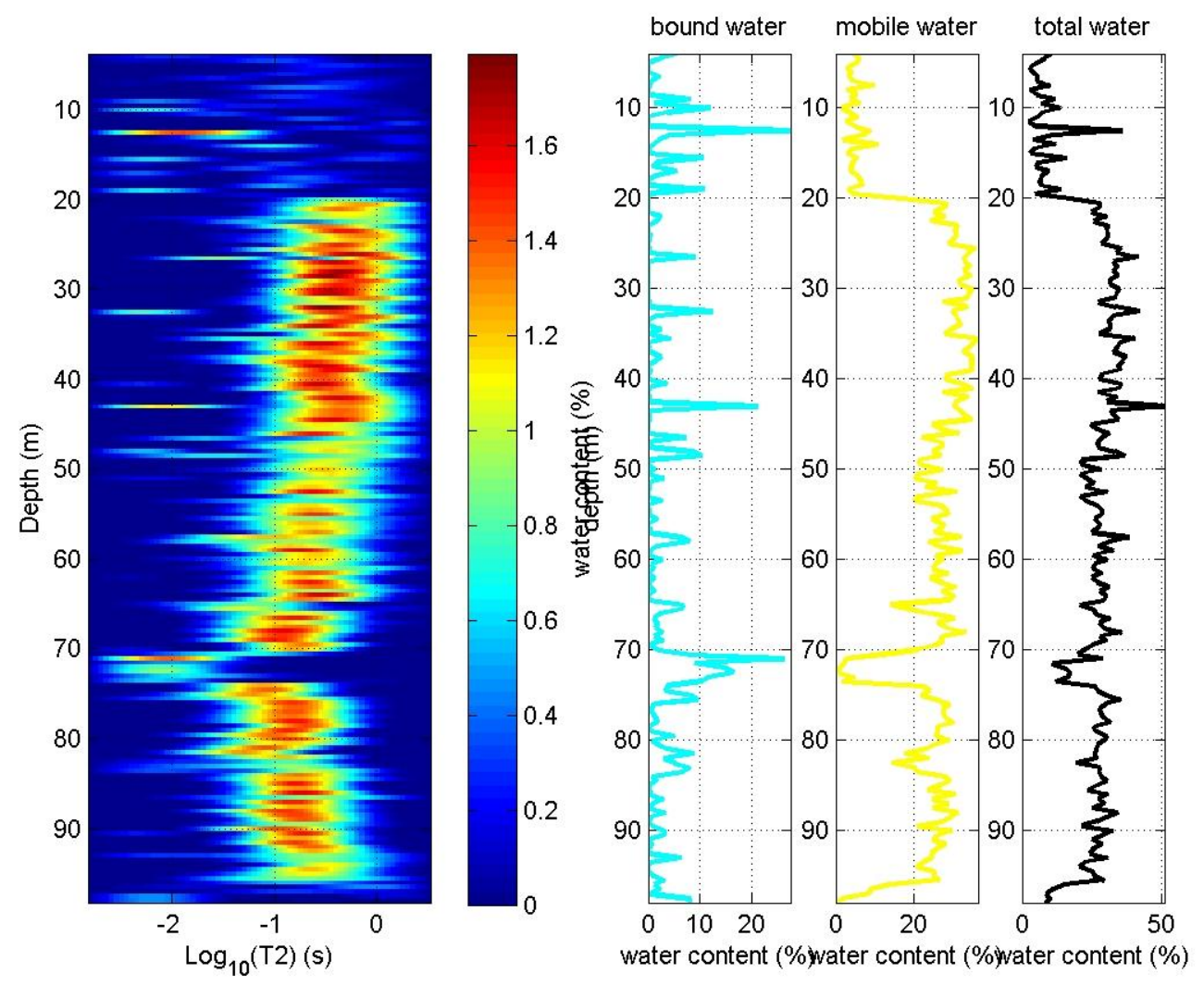

Figure 28: NMR log of MMR well \#03GB1060, May 26 and 28, 2010.

The next borehole on MMR was a 6" diameter PVC well situated in a wooded area. A photo of the NMR instrumentation at this site is shown in Figure 29. This well is labeled FSW0060, and has a maximum loggable depth of 18 meters. The standing water level in the well was $3.7 \mathrm{~m}$ below ground surface. We logged this well from a depth of $1 \mathrm{~m}$ to the maximum depth of $18 \mathrm{~m}$ using the following parameters:

Cable length $=470$ feet 
Echo spacing $=2.5 \mathrm{~ms}$

$\operatorname{Tr}=6 \mathrm{~s}$

N_stack $=25$ per depth interval

5 minutes per depth interval

$0.5 \mathrm{~m}$ intervals

logging rate $=6.0 \mathrm{~m} /$ hour

total logging time $=3.5$ hours

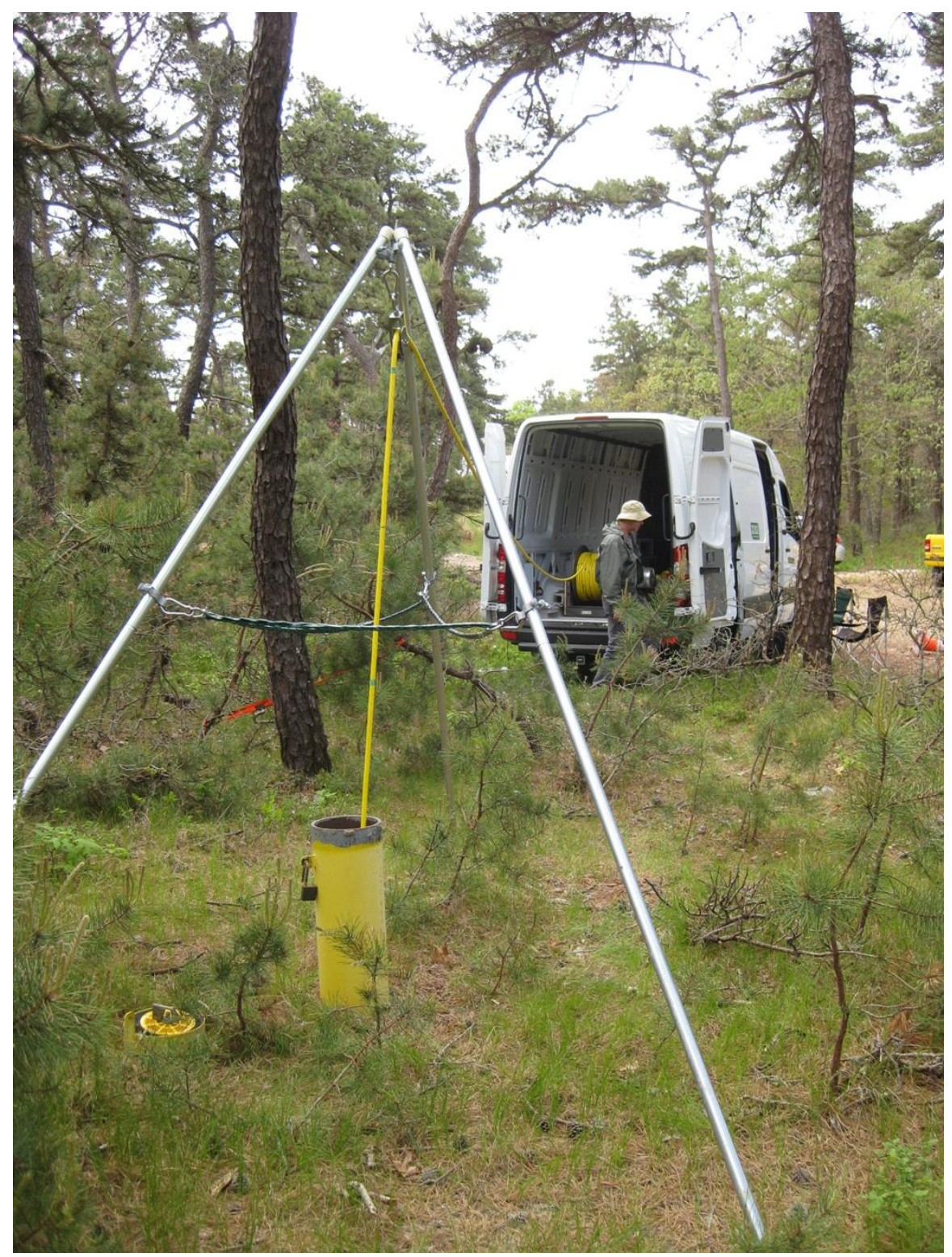

Figure 29 NMR instrumentation at MMR well \#FSW 545-0060.

The NMR log of FSW 545-0060 is shown in Figure 30. The NMR log indicates a probable silt later at $16-16.5 \mathrm{~m}$, and possible increased silt content at $6 \mathrm{~m}$ and $8 \mathrm{~m}$. 


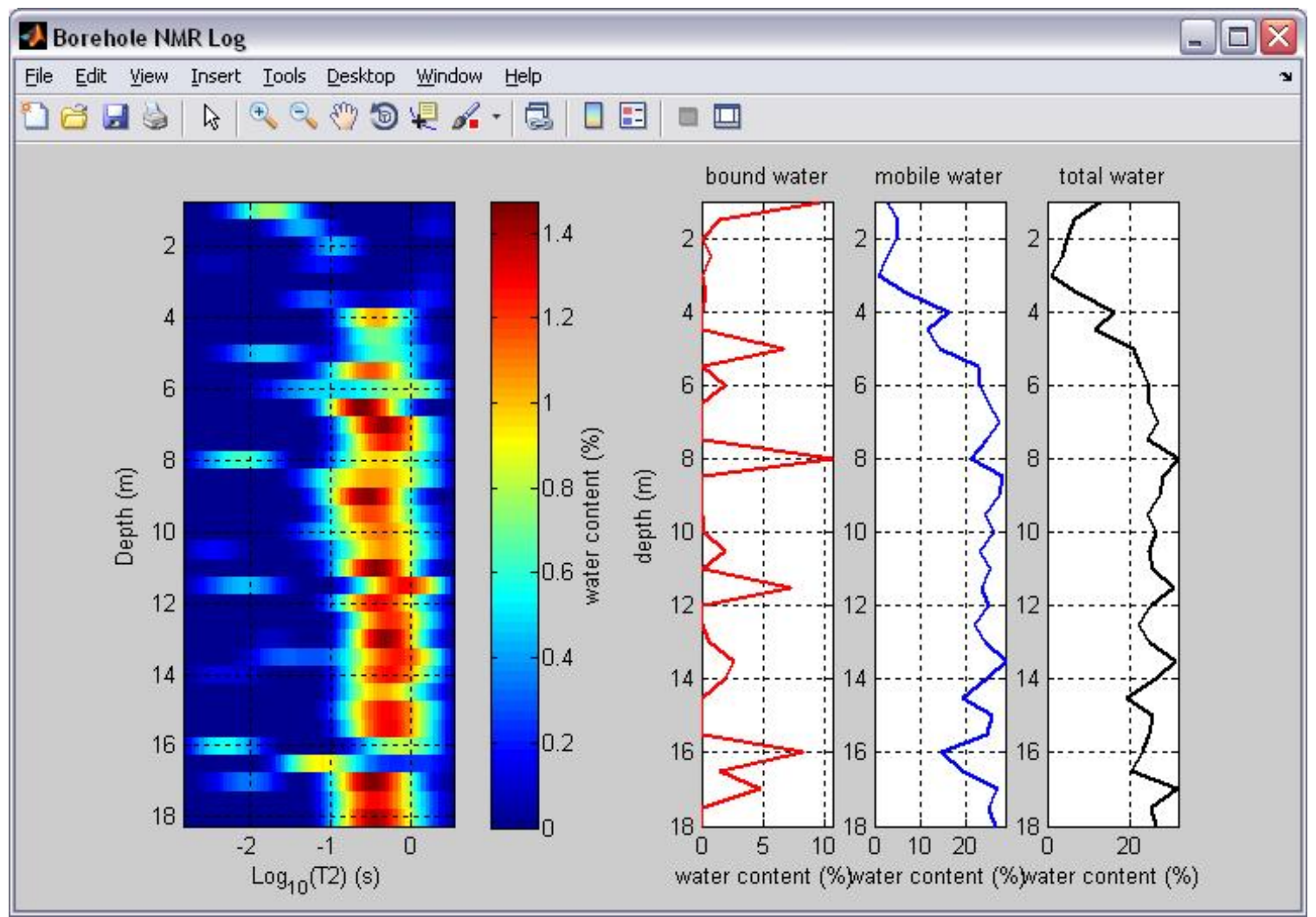

Figure 30: NMR log of FSW 545-0060, April 27, 2010.

The final borehole on MMR was an 8" diameter PVC well situated in a dense well field called the "gravel pit". This well is labeled FSW0060, and has a maximum loggable depth of 22.5 meters. The standing water level in the well was $4.7 \mathrm{~m}$ below ground surface. We logged this well from a depth of $3 \mathrm{~m}$ to the maximum depth of $22.5 \mathrm{~m}$ using the following parameters:

Cable length $=470$ feet

Echo spacing $=2.5 \mathrm{~ms}$

$\operatorname{Tr}=6 \mathrm{~s}$

N_stack $=25$ per depth interval

5 minutes per depth interval

$0.5 \mathrm{~m}$ intervals

logging rate $=6.0 \mathrm{~m} /$ hour

total logging time $=3.5$ hours

This well was logged from the bottom up. By the time we raised the probe above the standing water we saw, attached to our probe, an old corroded drilling rod, perhaps 1.5" in diameter and 8 feet long. Apparently this drill rod was initially sitting at the bottom of the well, and was stuck to our NMR probe the entire time we were logging this well. The presence of this large iron object surely distorted the static and alternating magnetic fields of the probe, so the NMR log data from this experiment are not reliable. But for completeness we present this NMR $\log$ data in Figure 31. Unfortunately the drill rod fell 
back down the well as we pulled the NMR probe from the top of the casing, and before we could get a photo of it.
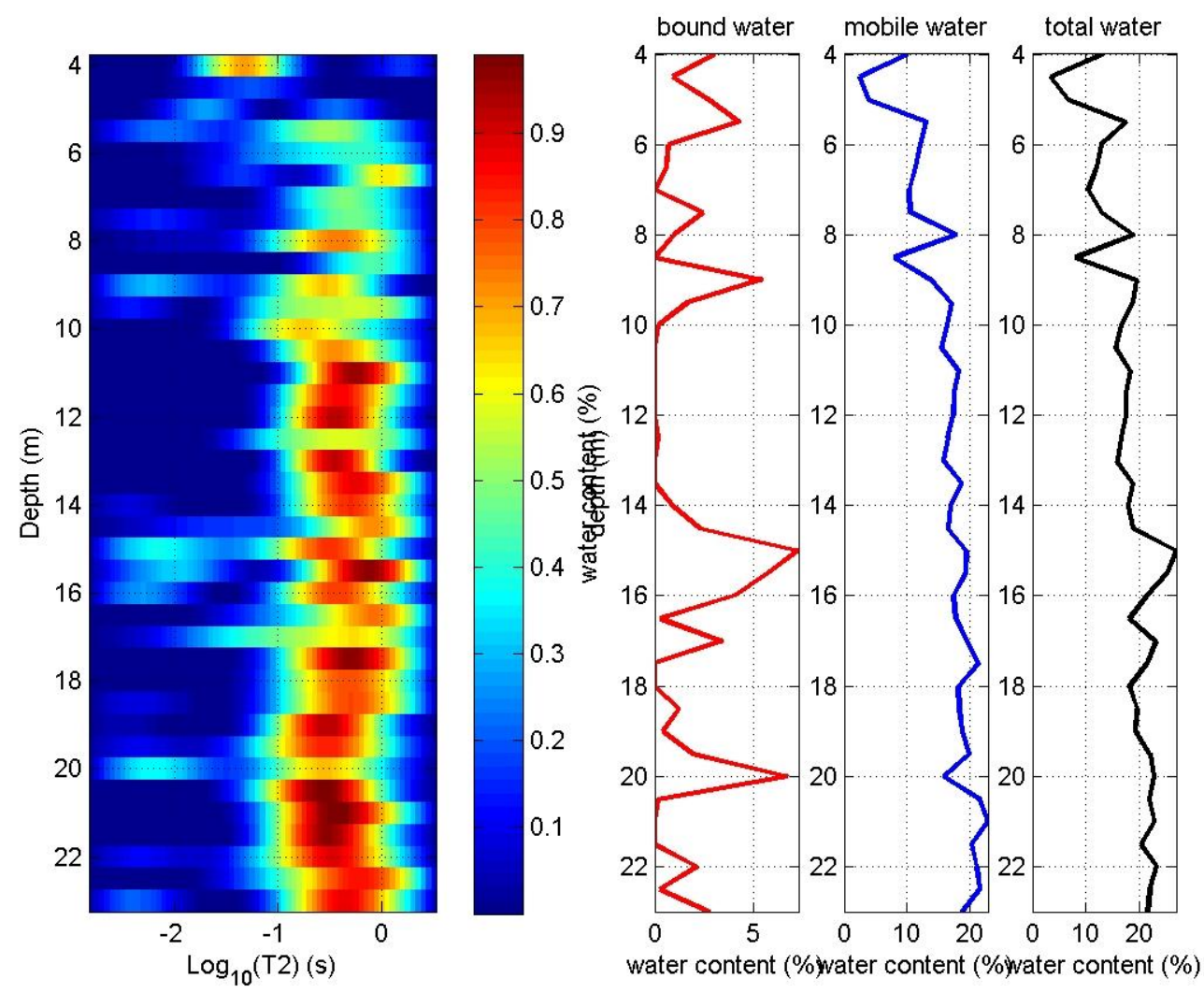

Figure 31: NMR log of FSW 507-80, April 27, 2010. Note: a steel drilling rod was stuck to the NMR probe during this $\log$, so these data are not reliable.

\section{2" Borehole and Direct Push NMR Instruments}

\subsection{7" Diameter Borehole Probe:}

We completed the assembly and laboratory testing of a 1.67" diameter borehole NMR sensor. A photo of the 1.67" diameter borehole probe is shown in Figure 32. This probe is longer, and has a detection coil length of $1.0 \mathrm{~m}$ and the same vertical resolution. The longer coil is a tradeoff which enables increased signal to noise ratio and increased logging speed at the expense of spatial resolution. The 1.67" probe also includes a remote switchable tuning circuit, to enable detection at two frequencies, and in two different concentric cylindrical shells. This can essentially double the logging speed.

We are currently operating this probe at $250 \mathrm{kHz}$ and $300 \mathrm{kHz}$. Laboratory NMR data obtained at $250 \mathrm{kHz}$ in our calibration water tank are shown in Figure 34, with an effective water content of $50 \%$. This data set was obtained with an echo spacing of 1.25 ms, which is the fastest echo spacing we have achieved to date. From this level or data 
quality we anticipate to achieve acceptable data quality at logging speeds of $1 \mathrm{~m} / \mathrm{hr}$ to $3 \mathrm{~m} / \mathrm{hr}$ with this probe.

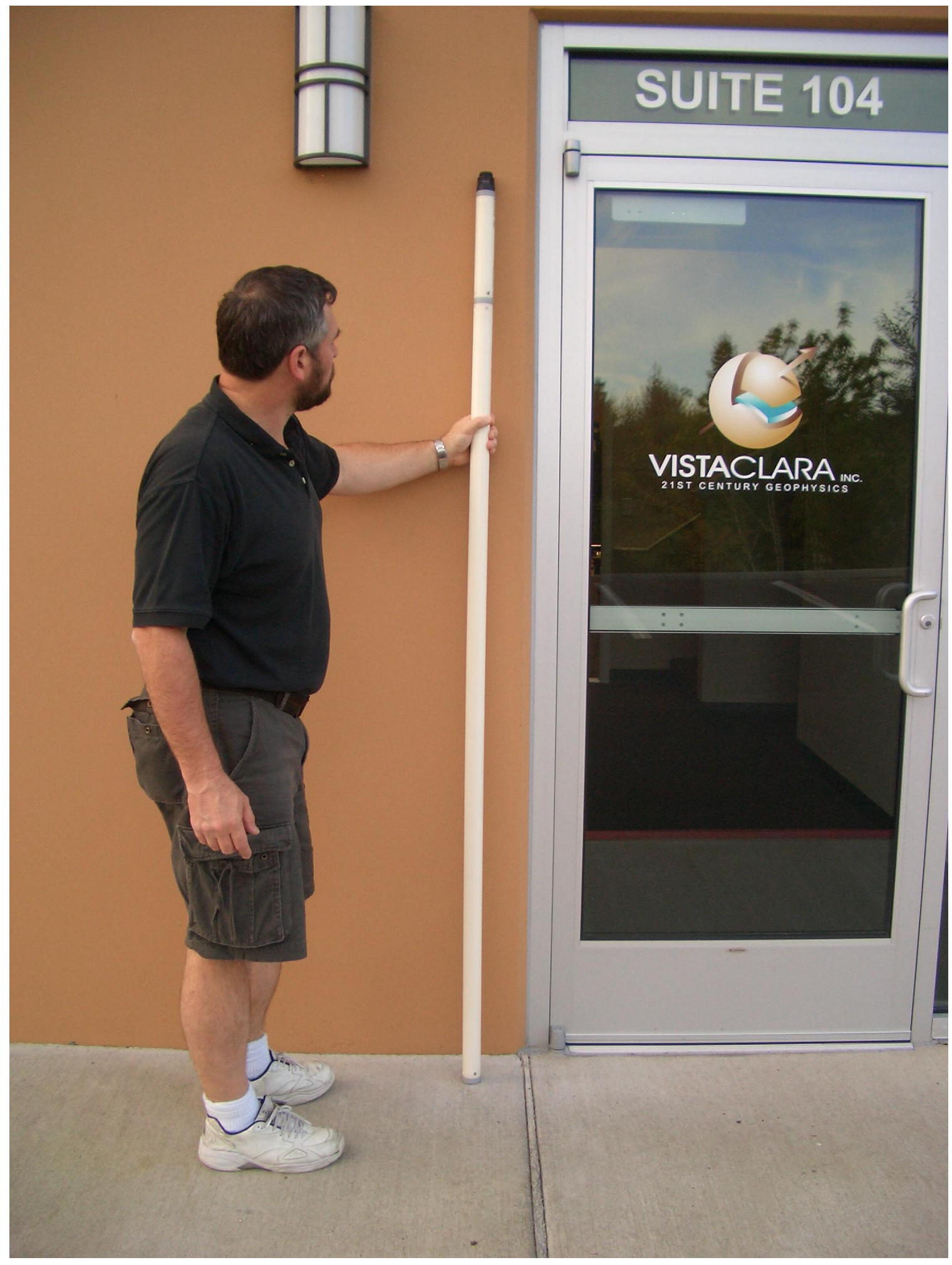

Figure 32: Photo of 1.67" diameter borehole NMR probe. 


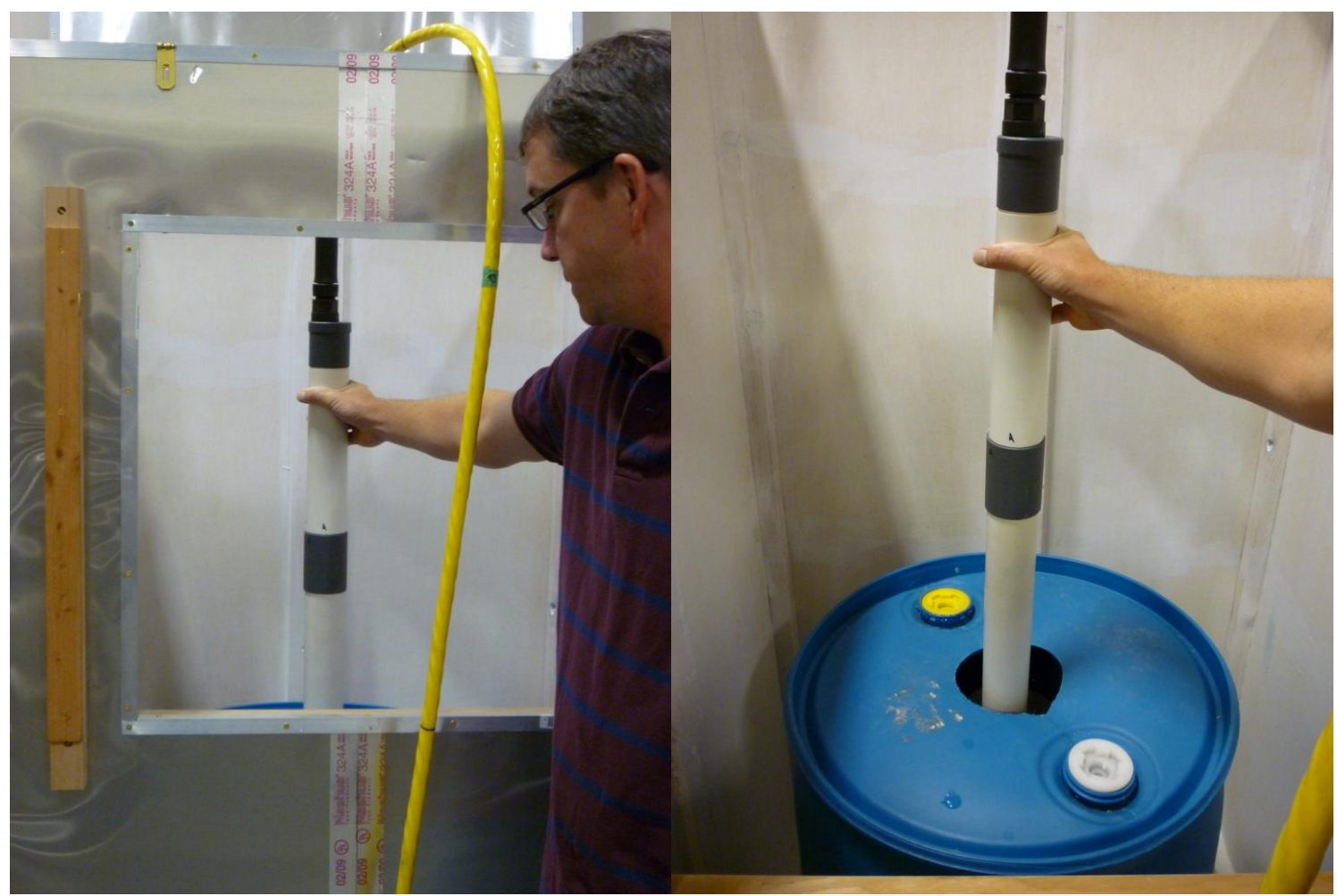

Figure 33: Calibration tank used for testing and calibrating the response of individual probes to water content of $50 \%$ or $100 \%$. The 2.5 " Geoprobe probe is shown in this photo. The blue 55 gallon plastic barrel is filled with water. 



Figure 34: Spin echo data obtained with 1.67" diameter NMR probe in 50\% effective water content in a laboratory calibration tank, using a $1.25 \mathrm{~ms}$ echo spacing. 


\section{5" Geoprobe NMR Probe:}

In the original Phase 2 proposal, we described our plan to work with a subcontractor to develop a direct push NMR probe that would be driven into the ground by a cone penetrometer machine and perform NMR measurements as the sensor was advanced into the ground. Over the course of the first year of the Phase 2 program, it became apparent that the originally-proposed approach was going to require exotic metals and expensive fabrication methods in order for the NMR probe to survive the hammering forces of the cone penetrometer machine. Even at this significant expense, it was not assured that the approach would succeed.

Towards the end of the first program year, Vista Clara's Chief Engineer Peter Turner suggested that we might be able to use a direct push machine to create the hole in the ground, and then lower a smaller diameter NMR probe down the middle of the drill rods and perform NMR logging in the hole as the drill rods were pulled out. We contacted Geoprobe Inc., and discussed the two approaches with them and they highly recommended the second option and informed us that they had already developed this type of geophysical logging and even developed geophysical probes, attachments and expendable cone tips to perform these types of measurements.

We asked for and received approval from the DoE program manager to change the plan to develop the second option, and switch subcontractors from the original vendor to Geoprobe. A purchase order in the amount of $\$ 10,000$ was issued for Geoprobe to design, assemble and test packaging for a downhole NMR probe that could be deployed with a geoprobe machine. The project PI (Dave Walsh) met with Tom Christy (VP of Geoprobe) and Wes McCall at Geoprobe in Salina KS on April 9, 2010. We went spent most of a day discussing the engineering specs and requirements for the Geoprobe version of our downhole NMR probe. We had our 3.5" diameter probe with us, and we performed an experiment by lowering that probe inside one of Geoprobe's larger diameter direct push rods, to see if the magnetic force of the sensor would cause it to stick to the inside of the carbon steel drill rods. The sensor did in fact stick to the inside of the drill rod, but with a small amount of downward force it slid down the inside of the rod. From this we concluded that the Geoprobe based NMR probe would have to have an attachment on the top so that an extendable rod could be attached and used to push the sensor down the center of the drill rods.

In May and June 2010 Geoprobe developed a preliminary design for the probe head, based on a waterproof connection for a single trunkline. We modified this design to incorporate the waterproof cable connector that we had selected for the borehole NMR tools. Geoprobe manufactured and delivered two complete probe packages, one of which is shown in Figure 35. These were delivered in July 2010. Geoprobe also tested the packaging to 60 PSI and also lowered it though Geoprobe drill rods to a depth of 60 feet. Vista Clara has started to assemble the internal electronics. As of September 2, 2010 we have about $3-4$ days of assembly and laboratory testing remaining. 


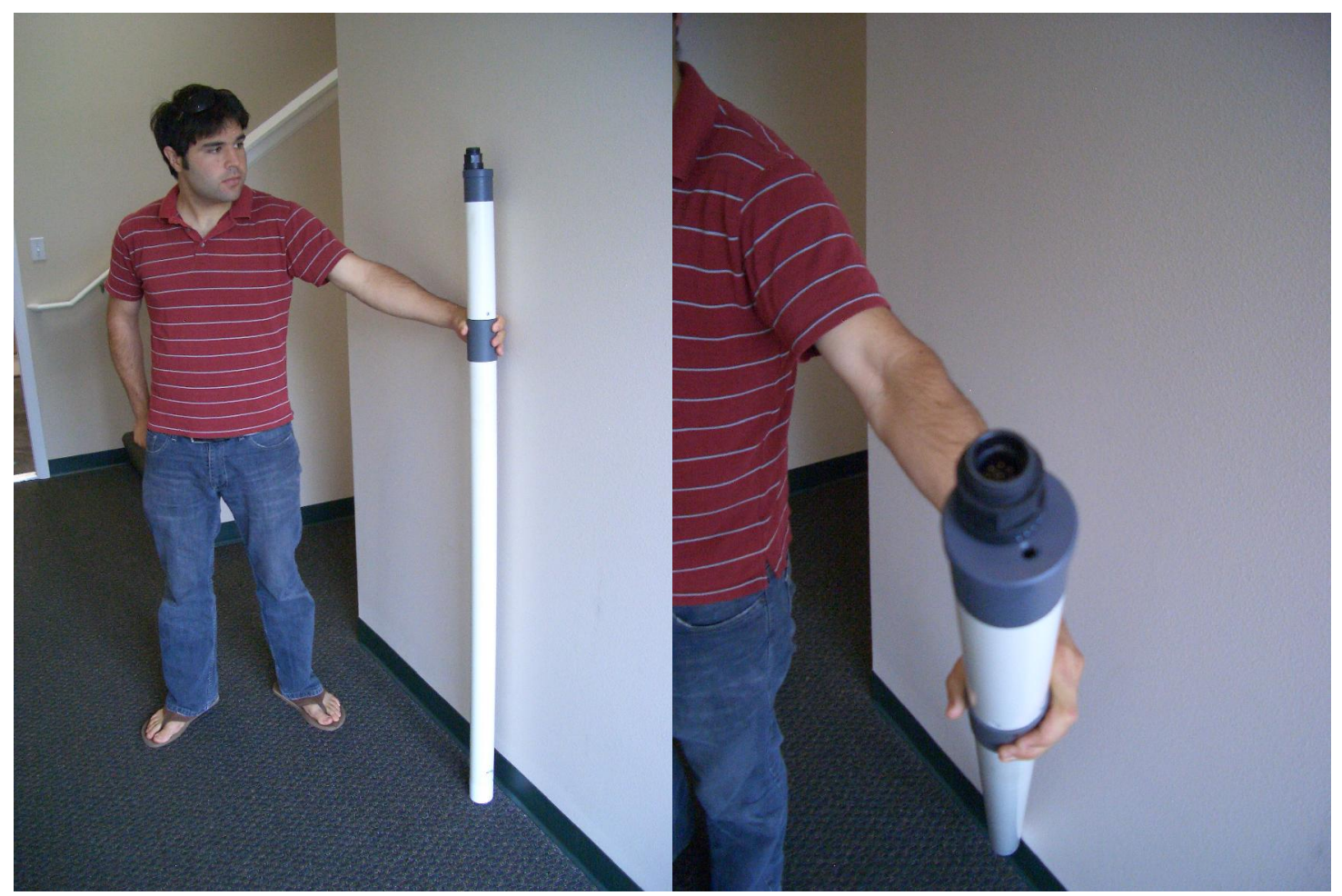

Figure 35: Geoprobe-supplied packaging for direct push NMR logging. Photo at right shows the waterproof cable connector we are using on all NMR probes.

\section{Budget and Performance Schedule:}

The Phase 2 program ended on August 13, 2010, and all charging to the grant ended on August 13, 2010. We ended up using our entire budget within the original Phase 2 program period, and we also reallocated a significant amount of program funds between subcontractors, and reduced the total subcontract funds. Since August 13, 2010 we have continued to work on completion of the 1.67 " probe and 2.5 " Geoprobe probe, and this continuing work has been funded using a portion of the $7 \%$ fee that we earned on this Phase 2 grant.

\section{Publications}

We submitted an abstract to the 2010 meeting of the American Geophysical Union, based on the work performed in this DoE Phase 2 grant. We also provided some of our borehole NMR data to Stanford University, and Rosemary Knight has submitted a Journal Article containing borehole NMR data collected as part of this Phase 2 SBIR. The borehole NMR tools developed under this SBIR effort, and results of the Phase 2 field tests, are also displayed prominently on the Vista Clara website: www.vista-clara.com. 


\section{Commercialization Status}

The NMR logging tools developed under this Phase 2 grant are now marketed under the tradename "Javelin" (http://www.vista-clara.com/instruments_javelin.html). As of September 3, 2010 these tools were being advertised for sale on our company website and the tools have been integrated into Vista Clara's geophysical services business segment (http://www.vista-clara.com/ground_water_services.html).

Based on the results of the field tests in Connecticut and Massachusetts, The USGS Water Resources Division requested a quotation for purchase of a borehole NMR instrument. We have a customer in Germany who has also expressed interest in acquiring a borehole NMR instrument, and two customers in Australia who have requested quotes for performing initial demonstrations in Australia. Vista Clara is now offering commercial borehole logging services using our 3.5" diameter borehole NMR probe, and we will work the 1.67" and Geoprobe versions into our commercial services as soon as they have completed engineering and field testing. 